Review

\title{
A review of current evidence regarding the ICD-11 proposals for diagnosing PTSD and complex PTSD
}

\author{
Chris R. Brewin ${ }^{\mathrm{a}, *}$, Marylène Cloitre ${ }^{\mathrm{b}}$, Philip Hyland ${ }^{\mathrm{c}}$, Mark Shevlin ${ }^{\mathrm{d}}$, Andreas Maercker ${ }^{\mathrm{e}}$, \\ Richard A. Bryant ${ }^{\mathrm{f}}$, Asma Humayun ${ }^{\mathrm{g}}$, Lynne M. Jones ${ }^{\mathrm{h}}$, Ashraf Kagee ${ }^{\mathrm{i}}$, Cécile Rousseau ${ }^{\mathrm{j}}$, \\ Daya Somasundaram ${ }^{\mathrm{k}}$, Yuriko Suzuki ${ }^{1}$, Simon Wessely ${ }^{\mathrm{m}}$, Mark van Ommeren ${ }^{\mathrm{n}}$, \\ Geoffrey M. Reed ${ }^{\text {n,o }}$
}

a Department of Clinical, Educational and Health Psychology, University College London, London, UK

b Division of Dissemination and Training, National Center for PTSD, Menlo Park, CA, USA

c School of Business, National College of Ireland, Dublin, Ireland

d School of Psychology, University of Ulster, Coleraine, North Ireland

e Department of Psychology, Division of Psychopathology, University of Zurich, Switzerland

f School of Psychology, University of New South Wales, Sydney, Australia

${ }^{g}$ Meditrina Healthcare, Rawalpindi, Pakistan

${ }^{\text {h }}$ FXB Center for Health and Human Rights, Harvard School of Public Health, Harvard University, Cambridge, MA, USA

${ }^{i}$ Department of Psychology, Stellenbosch University, Stellenbosch, South Africa

j Department of Psychiatry, McGill University Health Center, Montreal, Canada

${ }^{k}$ University of Jaffna, Sri Lanka

${ }^{1}$ National Center of Neurology and Psychiatry, National Institute of Mental Health, Tokyo, Japan

m Institute of Psychiatry, King's College London, UK

n Department of Mental Health and Substance Abuse, World Health Organization, Geneva, Switzerland

o Global Mental Health Program, Columbia University Medical Center, New York, NY, USA

\section{H I G H L I G H T}

- Structural analyses suggest PTSD can be measured with 6 symptoms and 3 factors.

- Analyses distinguish a 3-factor PTSD from a 6-factor Complex PTSD.

- ICD-11 CPSTD is associated with greater functional impairment than PTSD.

- Rates of PTSD in adults under ICD-11 are likely to be lower than under DSM-5.

\begin{abstract}
A B S T R A C T
The World Health Organization's proposals for posttraumatic stress disorder (PTSD) in the 11th edition of the International Classification of Diseases, scheduled for release in 2018, involve a very brief set of symptoms and a distinction between two sibling disorders, PTSD and Complex PTSD. This review of studies conducted to test the validity and implications of the diagnostic proposals generally supports the proposed 3-factor structure of PTSD symptoms, the 6-factor structure of Complex PTSD symptoms, and the distinction between PTSD and Complex PTSD. Estimates derived from DSM-based items suggest the likely prevalence of ICD-11 PTSD in adults is lower than ICD-10 PTSD and lower than DSM-IV or DSM-5 PTSD, but this may change with the development of items that directly measure the ICD-11 re-experiencing requirement. Preliminary evidence suggests the prevalence of ICD-11 PTSD in community samples of children and adolescents is similar to DSM-IV and DSM-5. ICD-11 PTSD detects some individuals with significant impairment who would not receive a diagnosis under DSM-IV or DSM5. ICD-11 CPTSD identifies a distinct group who have more often experienced multiple and sustained traumas and have greater functional impairment than those with PTSD.
\end{abstract}

\footnotetext{
* Corresponding author at: Department of Clinical, Educational and Health Psychology, University College London, Gower Street, London WC1E 6BT, UK.

E-mail address: c.brewin@ucl.ac.uk (C.R. Brewin).
} 


\section{Introduction}

The diagnosis of posttraumatic stress disorder (PTSD) was first introduced in the 3rd edition of the Diagnostic and Statistical Manual (DSM) (American Psychiatric Association, 1980), proving immediately influential and leading to decades of important and innovative research. Subsequent editions of the DSM in 1987 and 2000 refined and improved the diagnosis, culminating in the most recent version, DSM-5 (American Psychiatric Association, 2013). Despite the popularity of the diagnosis, it has been controversial in some quarters and there have been persistent questions about whether its formulation in the DSM is optimal. The 11th revision of the World Health Organization's (WHO) International Classification of Diseases (ICD-11) is currently nearing completion (First, Reed, Hyman, \& Saxena, 2015). ICD adopts a public health perspective and is organized around maximizing clinical utility for the use of diagnoses worldwide. ICD-11 has proposed a substantially different approach to diagnosing PTSD, primarily simplifying the conceptualization of disorder but also distinguishing between basic and complex forms of the condition (Maercker et al., 2013). The dissemination of these proposals has led to important discussions in the field (Miller, Wolf, \& Keane, 2014). ICD-11 is scheduled for release in 2018, and in this article we review emerging evidence about the new formulation of PTSD and CPTSD that speaks to whether the proposals are useful in principle and whether revisions of this formulation may be necessary. Most of this evidence concerns adults; there are some data on children and adolescents and developmental formulations of the proposals are underway but detailed consideration of them is beyond the scope of this article.

By the time of DSM-III-R in 1987, PTSD was already one of the most complex diagnoses in the manual. It included 17 symptoms divided into three clusters, with different thresholds for each cluster, and two additional criteria concerning the nature of the stressor and the duration of symptoms. DSM-IV added another criterion, the presence of clinically significant distress or impairment. In DSM-5, the three symptom clusters were increased to four on the basis of factor analytic findings, three further symptoms were added, and a dissociative subtype was included for the first time. These successive changes resulted in a comprehensive description of the disorder, but have had several costs. One is that the diagnosis can now be based on over half a million different combinations of symptoms (Galatzer-Levy \& Bryant, 2013). Another is that even with the more limited symptom combinations in DSM-IV it has proved difficult for non-specialists to confidently identify and diagnose it, which may partly account for the finding that levels of recognition among non-psychiatric physicians are poor (Brewin et al., 2010; de Bont et al., 2015; Ehlers, Gene-Cos, \& Perrin, 2009; Liebschutz et al., 2007).

Many of the symptoms included as criteria for PTSD in the DSM-IV and DSM-5 overlap with other disorders: Sleep disturbance, concentration problems, and irritability are characteristic of generalized anxiety disorder (GAD); depression is characterized by these same three symptoms but also by negative beliefs about oneself and the world, selfblame, diminished interest in activities, detachment from others, and emotional numbing. It is therefore unsurprising that rates of comorbidity are very high, particularly with depression (Brady, Killeen, Brewerton, \& Lucerini, 2000). Studies investigating the correlates of different latent factors of PTSD have found that symptoms characteristic of anxiety and depression appear to be more strongly related to those factors reflecting general dysphoria rather than to the more specific aspects of PTSD reflecting re-experiencing, active avoidance, and hyperarousal (Byllesby, Durham, Forbes, Armour, \& Elhai, 2016; Contractor et al., 2014; Durham et al., 2015; Gootzeit \& Markon, 2011).

Other evidence for non-specificity comes from studies that have examined whether PTSD symptoms are more common following events that, according to the successive definitions adopted by the DSM, are traumatic as opposed to distressing (but non-traumatic). The option of removing the requirement that one be exposed to a traumatic event was contemplated by the DSM-5 Work Group (Friedman, Resick, Bryant, \& Brewin, 2011). Although this committee recognized that PTSD symptoms can develop following non-traumatic events, it decided to retain the traumatic event as a gatekeeper criterion for the diagnosis because "intrusion and avoidance symptoms are incomprehensible without prior exposure to a traumatic event" (p. 754). However, a recent meta-analysis (Larsen \& Pacella, 2016) showed that PTSD symptoms were only slightly more common following events defined as traumatic versus non-traumatic according to the DSM, and this advantage disappeared if subjective ratings of fear, helplessness, and horror (required in DSM-IV but not in DSM-5) were omitted. Moreover, the structure of DSM-5 PTSD symptoms is essentially the same whether or not individuals have experienced events meeting the criteria for a trauma (Zelazny \& Simms, 2015).

One implication that has been drawn is that many of the PTSD symptoms included in the DSM are general reactions to adversity rather than specific reactions to trauma (Brewin, 2003). This non-specificity in the clinical picture painted by the DSM is possibly one of the reasons why, although much is known about the biological correlates of PTSD, there are as yet no specific biomarkers for the condition (Lehrner \& Yehuda, 2014). For example, reductions in brain volume associated with PTSD have not been able to be distinguished from similar patterns associated with depression (Kroes, Rugg, Whalley, \& Brewin, 2011).

Such observations have led previous authors to question whether comorbidity would be reduced with a smaller symptom set consisting of those more specific to PTSD such as flashbacks, nightmares, startle, and hypervigilance (Davidson \& Foa, 1991). Another proposal (Spitzer, First, \& Wakefield, 2007) involved eliminating a symptom considered to be of doubtful validity (impaired recall of the trauma) as well as symptoms shared with depression and GAD (irritability, insomnia, difficulty concentrating, and markedly diminished interest). The effect of this suggested change on comorbidity with a variety of disorders was tested in three studies, two of which showed no significant differences relative to DSM-IV (Elhai, Grubaugh, Kashdan, \& Frueh, 2008; Grubaugh, Long, Elhai, Frueh, \& Magruder, 2010) whereas the third, conducted with an adolescent sample, suggested less comorbidity with depression associated with the Spitzer et al. symptom set (Ford, Elhai, Ruggiero, \& Frueh, 2009). In these studies, however, the samples meeting the DSM-IV versus the Spitzer et al. criteria for PTSD overlapped to a considerable extent, with most of the PTSD cases appearing in both. A clearer picture would be given by comparing non-overlapping samples who met the DSM-IV but not the Spitzer et al. criteria, or vice versa.

A final suggestion to decrease the symptom set (Brewin, Lanius, Novac, Schnyder, \& Galea, 2009) proposed requiring at least one of two symptoms specifically reflecting re-experiencing of the traumatic event in the present (corresponding to the DSM items assessing flashbacks or nightmares), at least one of two symptoms specifically reflecting active avoidance (corresponding to the DSM items assessing avoidance of internal thoughts or external reminders), and at least one of two symptoms (hypervigilance or exaggerated startle) reflecting the continuing sense of threat identified as characteristic of PTSD (Ehlers \& Clark, 2000). Under this proposal there are only 27 combinations of qualifying symptoms. As with the Davidson and Foa (1991) proposal, the intention was to include those symptoms that best discriminated PTSD from other disorders. A more detailed rationale for the choice of symptoms can be found elsewhere (Brewin, 2013; Brewin et al., 2009).

\section{ICD-11 proposals for PTSD and complex PTSD}

A modified version of the Brewin et al. (2009) formulation, along with many other changes to ICD-10 PTSD, have been incorporated in the proposed diagnostic requirements for PTSD in ICD-11 (Maercker et al., 2013). Exposure to trauma, defined as an extremely threatening or horrific event or series of events, is required. The essential feature of 
re-experiencing requires that the traumatic event is not just remembered involuntarily but is experienced as occurring again in the here and now, in the form of vivid intrusive images or memories, flashbacks, or repetitive dreams or nightmares. As in DSM-5, flashbacks are defined as existing on a continuum of severity such that they involve (rarely, at the more severe end) a complete loss of awareness of present surroundings and are equivalent (much more commonly, at the milder end) to vivid intrusive images and memories experienced as happening in the here and now. This distinguishes ICD-11 re-experiencing from more general intrusive memories (e.g., DSM-5 symptom B1), which are found in many psychiatric disorders (Brewin, Gregory, Lipton, \& Burgess, 2010; Bryant, O'Donnell, Creamer, McFarlane, \& Silove, 2011). Again similarly to DSM-5, verbal thoughts about the event are no longer a symptom of PTSD. If the person is unable to recall the trauma (for example, because of a head injury), an alternative proposed re-experiencing symptom is emotional distress on reminders of the traumatic event (DSM-5 symptom B4). Both avoidance and a heightened sense of threat are essential features of ICD-11. This is similar to the two deliberate avoidance items in DSM-5 (symptoms C1 and $\mathrm{C} 2$ ), and two items from the hyperarousal cluster related to an ongoing sense of threat (symptoms E4 and E5). In addition to requiring at least one symptom of re-experiencing, avoidance, and sense of threat, other features of the ICD-11 PTSD diagnosis are that the disorder has to be present for several weeks and there has to be significant functional impairment.

Another new development for ICD-11 is the proposal for a sibling disorder, Complex PTSD (CPTSD). This is, in part, a reformulation in more specific terms of the previous ICD-10 diagnosis F62.0 "Enduring personality change after catastrophic experience" (EPCACE) and, like its predecessor, describes the disturbances in self-organization that can sometimes result from multiple, chronic or repeated traumas from which escape is difficult or impossible (e.g., childhood abuse, domestic violence, torture, war imprisonment). The ICD-11 CPTSD diagnosis is comprised of six symptom clusters: three are shared with PTSD (reexperiencing, avoidance, and sense of threat) and three additional symptom clusters related to disturbances in self-organization (DSO), specifically: affect dysregulation, negative self-concept and difficulties in relationships.

In contrast to EPCACE, CPTSD does not require a demonstrable personality change. However, the problems associated with CPTSD which reflect disturbances in self-organization are expected to be sustained and pervasive, and occur in a variety of contexts. Another diagnosis that has previously been suggested to capture responses to chronic or repeated trauma is "Disorders of Extreme Stress Not Otherwise Specified" (DESNOS) which was included in the Appendix to DSM-IV (American Psychiatric Association, 2000). The DESNOS diagnosis has been operationalized using 48 possible symptoms, organized into 6 scales and 27 subscales (Pelcovitz et al., 1997). ICD-11 CPTSD shares a similar conceptual frame as DESNOS, particularly the emphasis on affect dysregulation, negative self-concept and relational difficulties and is in part empirically derived from it. However, the proposed CPTSD diagnosis is expected to be comprised of 12 symptoms, in line with the ICD-11 emphasis on clinical utility, which includes limiting the number of symptoms that make up a diagnosis.

The decision to ground the CPTSD diagnosis in core PTSD symptoms, as well as problems in self-organization, derived largely from review of the empirical literature. Results from the DSM-5 field trial investigating DESNOS revealed substantially higher rates of endorsement of symptoms representative of disturbances in affective, self, and relational domains among those with early-life chronic trauma relative to those with other types of trauma history (van der Kolk, Roth, Pelcovitz, Sunday, \& Spinazzola, 2005). The DSM-IV field trial data also found that nearly all of those who met criteria for DESNOS also met criteria for PTSD (Roth, Newman, Pelcovitz, van der Kolk, \& Mandel, 1997), supporting the decision to incorporate the PTSD symptoms into the ICD-11 CPTSD diagnosis. The selection of the DSO symptoms was based on identifying those symptoms most frequently endorsed in the DSM-IV DESNOS field trial (van der Kolk, Roth, Pelcovitz, \& Mandel, 1993) as well as those identified as most impairing by expert clinicians in a recent consensus survey on CPTSD (Cloitre et al., 2011).

In summary, ICD-11 CPTSD shares with EPCACE and DESNOS an emphasis on changes in self-organization and the expectation that these changes typically result from exposure to sustained or multiple traumas from which escape is difficult or impossible. In contrast to EPCACE, CPTSD does not describe these symptoms as personality changes and in contrast to DESNOS, the number of symptoms is relatively small. Unlike both disorders, CPTSD includes the three symptom clusters of re-experiencing, avoidance and threat. Lastly, in contrast to both disorders and consistent with ICD-11 PTSD, functional impairment is explicitly identified as a requirement for the disorder.

It has been debated whether or not complex PTSD is actually PTSD comorbid with Borderline Personality Disorder (BPD). The proposed diagnostic requirements for CPTSD include several features that can be clearly differentiated from BPD. While both disorders share symptoms related to problems in emotion regulation, they are quite distinct in other symptom domains. BPD is typically characterized by an unstable sense of self that alternates between highly positive or negative selfevaluation and by emotionally intense and unstable relationships that vacillate between idealizing and denigrating perceptions of others. CPTSD in contrast is defined by a stable, although deeply negative sense of self and perceptions of relationships as painful and generally avoided. The presence of a trauma history is not a requirement for a diagnosis of BPD, while it is a prerequisite for the diagnosis of CPTSD. Data supporting these and other definitional differences, including endorsement of suicidality are discussed under the section of the manuscript concerning construct validity for CPTSD.

\section{Evidence for proposed ICD-11 PTSD}

This section summarizes emerging evidence for the factor structure of PTSD, and for its prevalence, comorbidity, validity, and ease of use. One limitation of much of this evidence is that the new ICD-11 re-experiencing requirement does not map exactly onto the corresponding items written for DSM-IV or DSM-5 for which data are available. For example, symptom B1 in DSM-IV includes intrusive thoughts (now excluded from DSM-5 and ICD-11). In DSM-5 the B1 symptom refers more narrowly to spontaneous, recurrent memories of the event that usually include sensory, emotional, or physiological components. Although it does not specify that memories be re-experienced in the present, arguably it now encompasses more of the spirit of re-experiencing that is made explicit in ICD-11. ICD-11 re-experiencing has therefore usually been approximated by using DSM-based items assessing nightmares (B2) and flashbacks (B3), even though items assessing the latter are not written in a way that corresponds to how ICD-11 (or DSM-5) define them. An instrument that more accurately addresses the re-experiencing requirement is currently under development (Cloitre, Roberts, Bisson, \& Brewin, 2015). In contrast, the avoidance and sense of threat items are readily approximated using DSM-based measures.

\subsection{Factor structure}

Confirmatory factor analyses of PTSD symptoms have been widely conducted, in large part because of the division of symptoms in succeeding editions of the DSM into varying numbers of clusters. These analyses seek to demonstrate that the clusters correspond to distinct components of the overall diagnosis, and that individual symptoms are correctly assigned to their appropriate cluster. For example, factor analyses led to the decision to create an additional cluster in DSM-5 to distinguish the active avoidance from the numbing symptoms (Friedman et al., 2011).

In a sample of West Papuan refugees, a variety of DSM-based models were found to fit the data well, along with a correlated three-factor 
model of PTSD in-line with the ICD-11 formulation (Tay, Rees, Chen, Kareth, \& Silove, 2015). Another study assessed the performance of the proposed ICD-11 structure in Australian injury patients six years posttrauma (Forbes et al., 2015). The three-factor solution again provided an excellent fit to the data. In this sample, the correlation between reexperiencing and avoidance symptoms was very high, and a two-factor solution consisting of these symptoms combined plus a sense of threat factor provided fit results equal to those of the three-factor model. This more parsimonious structure was also tested in a sample of Finnish school students and again found to be superior to the three-factor model due to an exceptionally high correlation between re-experiencing and avoidance (Haravuori, Kiviruusu, Suomalainen, \& Marttunen, 2016).

One study assessed the factor structure of PTSD in a group of Austrians over the age of 60 who had experienced their trauma decades earlier (Glück, Knefel, Tran, \& Lueger-Schuster, 2016). The adequacy of a 1-factor solution (all six symptoms loading onto a single PTSD factor), the 2-factor solution as proposed by Forbes et al. (2015), and the ICD113 -factor solution was tested. In this sample all models fit the data very well, with one index of model fit favoring the 1 -factor model but three alternative indices favoring the 3-factor model.

In the most comprehensive comparison of different models conducted to date (Hansen, Hyland, Armour, Shevlin, \& Elklit, 2015), the ICD-11 3-factor structure was compared to the DSM-5 4-factor structure and to alternative 5-factor and 6-factor DSM-5 models in seven independent Danish trauma samples. These included bereaved parents, road traffic accident victims, paraplegia sufferers, physical assault victims, incest victims, sexual assault victims, and a mixed trauma sample receiving treatment. In contrast to the DSM-5 models, none of which demonstrated acceptable model fits, the ICD-11 model showed an excellent fit to the data in all samples except incest victims. Moreover, the fit was equally good for men and women. Similar support for the 3factor ICD-11 model was found in a study of former German political prisoners, using the Impact of Event Scale - Revised (Weiss \& Marmar, 1996) to model ICD-11 PTSD (Hyland, Brewin, \& Maercker, 2017). In this sample the three-factor model provided an excellent representation of the data, but a one-factor model and the two-factor model of Forbes et al. (2015) were rejected as poor representations of the data.

Finally, the ICD-11 model showed an excellent fit to the data as well as strong gender invariance in a study of pre-adolescent children exposed to Hurricane Ike (La Greca, Danzi, \& Chan, 2017). Overall, therefore, in the great majority of studies the ICD-11 3-factor solution has been at least as good as, if not better than, other ways of describing the structure of PTSD symptoms.

\subsection{Other structural analyses}

Instead of the traditional view that symptoms reflect underlying latent constructs, an emerging alternative perspective proposes that symptoms are causally related among themselves. Such relations are empirically tested by a data analytic technique known as network analysis. Four studies to date have conducted such analyses on the inter-relations among PTSD symptoms.

The first study, conducted with earthquake survivors in China (McNally et al., 2015), reported that, even after associations with all other variables were controlled, strong interconnections existed between intrusive memories, nightmares, and flashbacks, between avoidance of thoughts of the trauma and avoidance of activities reminiscent of the trauma, and between hypervigilance and exaggerated startle. A second study was conducted with Australian accident victims (Bryant et al., 2017). There were strong interconnections in the acute phase between flashbacks, intrusions, and avoidance of thoughts. At the 12-month assessment, the associations between re-experiencing symptoms were stronger, and physiological reactivity to trauma reminders was strongly associated with the startle response, which was also associated with hypervigilance. Thus, although the analyses reported by the first study were consistent with the 3-factor ICD-11 structure, the
Bryant et al. study found connections between re-experiencing and avoidance, reminiscent of the 2-factor structure of ICD-11 symptoms previously reported in this same sample by Forbes et al. (2015).

The third and fourth studies (Armour, Fried, Deserno, Tsai, \& Pietrzak, 2017; Mitchell et al., 2017) were both conducted with U.S. military veterans using the DSM-5 symptom set. Armour et al. reported especially strong connections between nightmares and flashbacks, and between hypervigilance and an exaggerated startle response. Similarly, Mitchell et al. reported strong connections between avoidance of external reminders and avoidance of thoughts and memories, between hypervigilance and an exaggerated startle response, and between intrusive distressing memories and distressing dreams. The studies differed markedly, however, in which symptoms appeared to be most central to the network with the exception that both identified the centrality of negative emotional state. As DSM-5 and ICD-11 PTSD are defined very differently, it is a matter of debate whether one would expect the ICD-11 symptom set to appear as central items in a network analysis that included all the DSM- 5 symptoms.

Another approach to assessing structure is to look for evidence that cases identified by a set of diagnostic rules form a distinct group who are qualitatively different from the rest of the sample, rather than simply having similar but more severe symptoms. In the past such taxometric analyses have not supported the idea that PTSD as diagnosed by the DSM does form a distinct category, but rather have suggested that it represents the upper end of a continuum (Broman-Fulks et al., 2006; Broman-Fulks et al., 2009; Forbes, Haslam, Williams, \& Creamer, 2005; Ruscio, Ruscio, \& Keane, 2002). A recent study conducted similar taxometric analyses both using DSM-IV and ICD-11 formulations of PTSD (Kliem et al., 2016). The authors replicated the dimensional solution previously found for DSM-IV, but the results suggested a categorical solution for ICD-11. The taxon group (corresponding to ICD-11 PTSD) reported more physical and mental symptoms, more suicidal thoughts relative to the remainder of the sample, and were more likely to be seeking treatment.

\subsection{Prevalence}

A number of studies, including one using World Mental Health Survey data from 13 countries and nearly 24,000 respondents (Stein et al., 2014), have now investigated prevalence rates by estimating the ICD-11 diagnostic requirements and comparing rates with those generated by ICD-10, DSM-IV, and DSM-5 formulations. These are listed in Appendix A. It can be seen that although the level of agreement between the presence or absence of a diagnosis using ICD-11 and the DSM is generally high, the prevalence in adult samples using ICD-11 is somewhat lower. ICD-11 rates are also reduced, to a larger extent, relative to ICD-10. A number of studies have identified that the diagnostic requirements for re-experiencing (Hyland et al., 2016; Morina, van Emmerik, Andrews, \& Brewin, 2014; Stammel, Abbing, Heeke, \& Knaevelsrud, 2015; van Emmerik \& Kamphuis, 2011), and hyperarousal (Hyland et al., 2016; Stammel et al., 2015; van Emmerik \& Kamphuis, 2011) are more stringent in ICD-11 than the DSM, whereas the requirements for avoidance are more stringent in DSM-IV than in ICD-11 (Morina et al., 2014; Stammel et al., 2015; van Emmerik \& Kamphuis, 2011). It is likely that the absence of non-specific symptoms such as intrusive thoughts and memories, which do not satisfy the ICD-11 requirement of re-experiencing, are responsible for the difference in prevalence rate relative to DSM-IV or DSM-5 (Hafstad, Thoresen, Wentzel-Larsen, Maercker, \& Dyb, 2017; Hyland et al., 2016; O'Donnell et al., 2014; Sachser \& Goldbeck, 2016).

Importantly, there is evidence that ICD-11 and DSM-5 identify only partially overlapping groups of cases, and that neither is comprehensive. This is not surprising because different diagnostic requirements would be expected to identify different individuals. For example, studies have noted the sometimes substantial lack of concordance between DSM-IV and DSM-5 diagnostic decisions for PTSD (Hafstad, Dyb, 
Jensen, Steinberg, \& Pynoos, 2014; Hoge, Riviere, Wilk, Herrell, \& Weathers, 2014). Each diagnostic system appears to find a number of comparably impaired individuals that the other does not although, in line with the difference in prevalence rates, DSM-IV and DSM-5 identify more unique cases than does ICD-11.

Data on children and adolescents need to be treated with caution owing to the possible need for changes to diagnostic requirements reflecting developmental concerns. For example, DSM-5 contains a new subtype of PTSD applicable to pre-school children. Further specification of diagnostic requirements for pre-school and pre-adolescent children are likely to follow within both ICD and DSM formulations.

An excess of PTSD cases diagnosed with DSM-IV relative to ICD-11, similar to that reported in adult samples, was found in a clinical sample of children and adolescents (Sachser \& Goldbeck, 2016). However, studies with community samples have reported different results. Prevalence rates in two samples of hurricane-exposed pre-adolescents were very similar using DSM-IV, DSM-5, and ICD-11 (Danzi \& La Greca, 2016). In this study both ICD-11 and DSM-IV identified a considerable number of cases that the other diagnostic systems did not. A study of PTSD related to school shootings in Finland found that ICD-11 identified slightly more cases than DSM-IV (Haravuori et al., 2016). Finally, Hafstad and colleagues studied young survivors of the Norwegian Utøya massacre and found that rates of PTSD were similar whether measured with ICD-11 or DSM-5 (Hafstad et al., 2017). Uniquely, the authors used the same instruments on their sample's parents, finding by contrast that in this older group rates of PTSD were much higher when measured with DSM-5 than with ICD-11. Further research is needed to determine whether this difference is best accounted for by the contrasting ages of the samples or by the fact that only one was directly exposed to personal life threat.

\subsection{Comorbidity, validity, and ease of use}

As discussed above, the most accurate estimate of the consequences of a new method of diagnosis is obtained by comparing cases who meet one set of requirements but not the other, and vice versa. Where this has been done, as shown in Appendix A, there is clear evidence that comorbidity with depression is significantly reduced under ICD-11. A similar analytic approach has rarely been applied to validity issues but, again as shown in Appendix A, there is some evidence that quality of life is lower under ICD-11 than ICD-10 PTSD, and that pure ICD-11 cases are associated with higher levels of distress or impairment than cases diagnosed using other methods. More generally, there is little evidence that the association of ICD-11 PTSD with anxiety, depression, or other indicators of psychological distress and well-being, differs substantially from that of other ways of diagnosing PTSD.

Field trials were conducted to test the ease of use of the new diagnoses through an internet-based study involving mental health professionals from many parts of the world (Keeley, Reed, Roberts, Evans, Medina-Mora, et al., 2016; Keeley, Reed, Roberts, Evans, Robles, et al., 2016). A sample of 1738 mental health professionals participated and rated pairs of vignettes that contrasted features of ICD-10 and ICD-11 diagnostic guidelines for PTSD. One pair contrasted the symptom of reexperiencing in the present with more general intrusive memories of the traumatic event. The majority of professionals were more likely to diagnose PTSD if there was re-experiencing in the present, but this occurred to an equivalent extent under ICD-10 and ICD-11, suggesting that this distinction was already in clinicians' minds. However, those endorsing ICD-11 PTSD from the vignette that did not contain re-experiencing in the present were likely to express doubt over this symptom, suggesting a need for greater clarity or education concerning the concept. Similar results were obtained when the pair of vignettes contrasted a presence versus a lack of functional impairment.

The Keeley et al. study also found that discrimination between PTSD and adjustment disorder was better under ICD-11 than ICD-10. Importantly, a tendency was detected on the part of some clinicians to base diagnoses on the type of stressor event rather than on the specific pattern of symptoms. Overall, the data indicated that the ICD-11 diagnostic rules are viable but that educational efforts will be needed - as with the introduction of any new diagnostic system - to have clinicians understand and apply them in a consistent way. The proposed ICD-11 diagnostic guidelines for Disorders Specifically Associated with Stress were revised based on the results of the Keeley et al. study, and are currently available for review and comment at https://gcp.network/ en/icd-11-guidelines.

\subsection{Summary}

A substantial amount of preliminary data from many parts of the world are now available based on estimates of the proposed ICD-11 PTSD diagnosis derived from existing instruments. These suggest the following interim conclusions. First, the proposed three-factor structure of PTSD, operationalized with two core symptoms representing each factor, routinely provides a very good fit to the data, although there may be some populations (e.g., incest victims or physically injured accident victims) where the fit is not optimal. Second, consistent with the new requirement for functional impairment, prevalence rates are considerably less than ICD-10. Third, consistent with the more narrow formulation of ICD-11 PTSD, prevalence rates are significantly reduced relative to DSM-IV and DSM-5 in adults, although very preliminary evidence on some age groups suggest that there are no consistent differences in children and adolescents. These lower prevalence rates, however, are based on estimates derived from instruments not designed to measure ICD-11 re-experiencing, and may change in the future. ICD11 PTSD does not just identify a subset of cases diagnosed with DSM-IV or DSM-5, but detects some who would not be diagnosed using the other systems. Fourth, comorbidity with depression appears to be reduced under ICD-11. Fifth, initial evidence of validity suggests that ICD11 PTSD detects cases who are of approximately equal severity to DSMIV and DSM-5 cases and who are on average more severe than ICD-10 cases.

\section{Evidence for proposed ICD-11 complex PTSD}

\subsection{Construct validity}

An important initial question regarding the proposed CPTSD diagnosis is whether, in fact, CPTSD describes a class of individuals who are distinct from those with PTSD and who differ from those with PTSD by having a more "complex" symptom profile comprised of a greater number and type of clinically significant symptoms. The distinction between PTSD and CPTSD has been supported in several latent class and latent profile analyses. To date, 10 studies (see Appendix B) have been published and 9 of them identified the presence of at least two distinct symptom profiles, one describing a group of individuals endorsing high levels of CPTSD symptoms in all six clusters (re-experiencing, avoidance, sense of threat, affect dysregulation, negative selfconcept, and disturbances in relationships), and another reporting high levels of PTSD symptoms but low levels of symptoms related to DSO.

Two of the nine studies concern children and adolescents and, similar to the findings among adults, have reported distinct classes of PTSD and CPSTD, in one study among a community sample of adolescents and young adults (Perkonigg et al., 2016), and in the other among a clinical sample of children and adolescents (Sachser, Keller, \& Goldbeck, 2016). The presence of distinct symptom profiles as early as childhood and adolescence is of interest, particularly in regard to whether there are developmentally sensitive and specific risk factors that may differentially contribute to each of the symptom profiles. Little is known to date; contributors may include not only trauma history but also individual genetic vulnerability, the social environment, including caregivers, or some combination of these factors.

Differences in latent class and latent profile analyses are observed 
depending on whether the study evaluates clinical or community samples. Studies of clinical samples (Cloitre, Garvert, Brewin, Bryant, \& Maercker, 2013; Karatzias et al., 2016; Sachser et al., 2016) have identified only 2 or 3 classes, which typically represented a PTSD profile, a CPTSD profile, and occasionally a third profile low on all symptoms, describing what might be viewed as a resilient group. Community studies with larger samples (Perkonigg et al., 2016) or those with highly diverse samples (Palic et al., 2016) identified four or more classes. Smaller samples like those found in the clinical studies tend to have solutions with fewer classes, while more broadly representative samples tend to have solutions with a larger number of classes (Perkonigg et al., 2016). The additional classes in the community samples tended to be low on PTSD symptoms and moderately high on DSO symptoms, suggesting the presence of a group or groups that might be experiencing other disorders such as depression, anxiety, substance abuse and dissociative disorders that are known to include a substantial proportion of trauma-exposed individuals.

One study with findings contrary to the above was reported by Wolf et al. (2015). Using a general population sample meeting diagnostic requirements for lifetime PTSD and a sample of trauma-exposed military veterans, the authors reported that factor-mixture modeling (FMM) found the best fit to be associated with a two-dimensional four-class model in which classes differed by severity rather than type of symptoms: Those reporting high PTSD symptoms also reported high DSO symptoms and those with low PTSD symptoms reported low DSO symptoms. The authors concluded that the FMM findings undermined the validity of a distinction between PTSD and CPTSD. However, such a conclusion could be questioned on the basis of how the DSO symptoms were measured and the specification and interpretation of the FMM solutions.

First, the seven symptoms used to represent the DSO profile are different from those in the proposed formulation of CPTSD (Cloitre et al., 2013) and used in the above published studies, suggesting that the comparability of the Wolf et al. study to the other studies is uncertain. Second, the results reported by Wolf et al. (2015) specified and tested a particular type of FMM. Other specifications were possible (Muthén, 2008) but not tested, and these might have produced different results. Overall, while the FMM is of interest, the study results and conclusions must be taken with caution.

There is some evidence emerging regarding the discriminant validity of CPTSD as compared to Borderline Personality Disorder (BPD). An LCA study of 310 treatment-seeking victims of childhood sexual and/or physical abuse identified four classes each with distinct symptom profiles: a group with BPD, a group with ICD-11 CPTSD but no BPD, a group with ICD-11 PTSD, and a Low Symptom group (Cloitre, Garvert, Weiss, Carlson, \& Bryant, 2014). In the BPD class, 92.0\% of its members fulfilled criteria for DSM-IV BPD while in the CPTSD class 77.8\% fulfilled the ICD-11 diagnostic requirements for CPTSD with only $7.8 \%$ meeting criteria for DSM-IV BPD. The symptoms that distinguished risk for BPD as compared to CPTSD most strongly were: frantic about abandonment, unstable sense of self, unstable relationships, and impulsiveness, characteristics that were not salient to the CPTSD profile. In the CPTSD profile, the endorsement pattern indicated an extremely negative sense of self with no significant shifts in identity. Relationships were perceived as painful and to-be-avoided. While both disorders reference difficulties with sense of self and relationships, the content of the problems are distinct. Lastly, while nearly half of those in the BPD class endorsed self-harm and suicidal behaviors (48.7\%), the rate was much lower in the CPTSD class and equivalent to that in the PTSD class $(C P T S D=14.3 \%$, PTSD $=16.7 \%)$. Suicidality and selfharm are prominent in the symptom profile and treatment of BPD while in CPTSD, as in PTSD, these behaviors occur significantly less frequently and are not included in the diagnostic definition.

Additional support for the BPD versus CPTSD distinction comes from a network analysis of BPD, PTSD and DSO symptoms where a map of symptoms showed that those related to BPD clustered together and at a distance from and weakly related to both PTSD and DSO symptoms which were strongly related to each other (Knefel, Tran, \& LuegerSchuster, 2016).

\subsection{Factor structure}

To date, seven confirmatory factor analyses of ICD-11 CPTSD symptoms have been published. An initial four-factor model comprised of PTSD, affect dysregulation, negative self-concept, and disturbances in relationships was a good fit to the data in a sample of treatmentseeking individuals who had experienced interpersonal violence (Cloitre et al., 2013). However, the theoretical basis of the diagnosis is that the PTSD and DSO components contribute to CPTSD as higher order factors, with each higher order factor in turn supported by three first order factors corresponding to the symptom clusters. Four studies have systematically investigated possible models for organizing the symptom clusters, including the two-factor higher order models, all of them evaluating treatment-seeking individuals who had experienced some type of interpersonal violence (Hyland et al., 2017; Hyland et al., 2017; Karatzias et al., 2017; Shevlin et al., 2017). The key contrasts concern three possible models: a factor structure in which all the six symptom clusters are correlated with each other in a non-hierarchical fashion, a single higher-order factor supported by the six clusters, and a two-factor model represented by PTSD and DSO (see Fig. 1). The twofactor higher-order model comprised of the PTSD and DSO provided the best fit to the data in all four studies. The results support the conceptual coherence of the CPTSD diagnosis as being comprised of two distinct but related components.

Finally, two studies evaluated the factor structure of CPTSD in refugees. In Tay et al.'s (2015) sample of West Papuan refugees, the analytic plan was organized such that the first analyses simply assessed whether the symptoms of CPTSD were related to each other in a nonhierarchical fashion. If this was successful, a higher-order, single factor analysis would be conducted. Analysis of CPTSD as a six-factor structure fit the data. The next analysis, assessing a one-factor higher-order structure (CPTSD) with six first order factors was not as strong, leading to the conclusion that the six factors did not cohere under a unitary CPTSD construct. However, the authors did not test CPTSD as a twofactor higher order model comprised of PTSD and DSO, consistent with the formulation described in the previous paragraph. In contrast, a later study of 134 refugees in Switzerland from a variety of countries of origin directly compared the one and two higher-order factor CPTSD models and found that the two-factor model was superior as well as having a very strong fit to the data (Nickerson et al., 2016). The factor analytic studies on refugees and child abuse survivors are consistent overall and support the conceptualization of CPTSD as being comprised of two over-arching components, PTSD and DSO.

\subsection{Prevalence}

Given that the development of a reliable measure for ICD-11 PTSD and CPTSD is currently underway, the identification of prevalence for each of these disorders can only be roughly estimated and is likely to change. However, certain patterns can be noted that are consistent with prevalence rates for previous formulations of PTSD. Specifically, prevalence ranges vary as expected depending on the sample. Following the taxonomic proposal of PTSD and CPTSD as sibling diagnoses, individuals can be diagnosed with either one or the other diagnosis but not both. Using this guideline, estimates for PTSD reported by community and nationally representative samples range from $2.3 \%$ to $3.0 \%$ while those for CPTSD range from $0.6 \%$ to $1.0 \%$ (Hyland et al., 2017; Wolf et al., 2015). Estimates are substantially higher in clinical settings. To date, prevalence rates of $7.8 \%$ to $37 \%$ for PTSD and $32.8 \%$ to $42.8 \%$ for CPTSD have been reported in samples assessed in trauma clinics (Hyland et al., 2017; Karatzias et al., 2016; Nickerson et al., 2016). Based on these numbers it may be that, in general, community rates of 


\section{CPTSD Model 1: Six Symptom Clusters Correlated with Each Other}

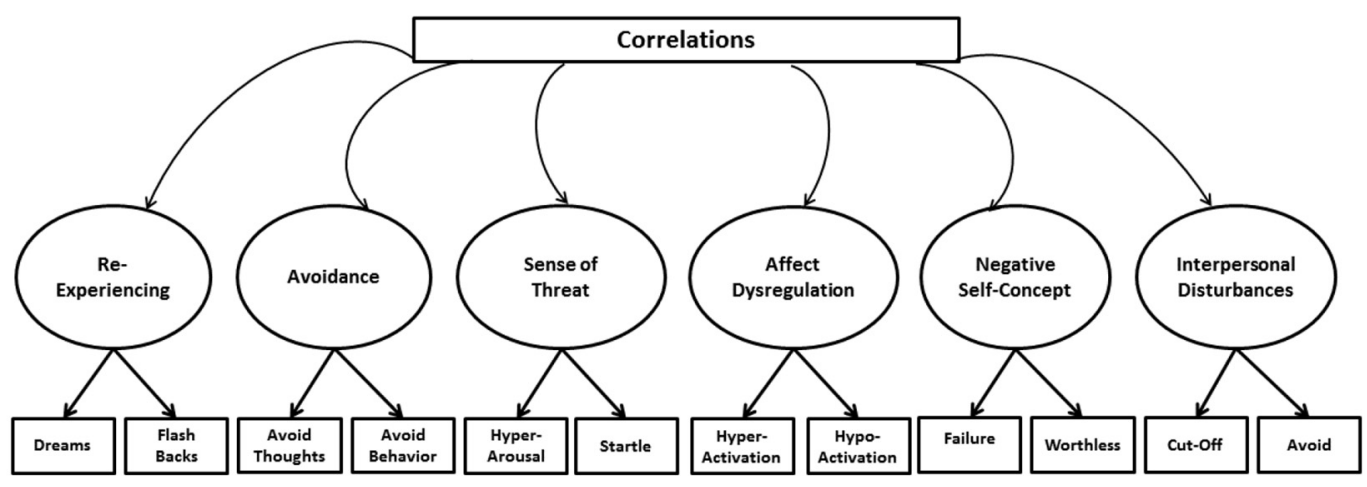

CPTSD Model 2: Single Higher Order Factor Model

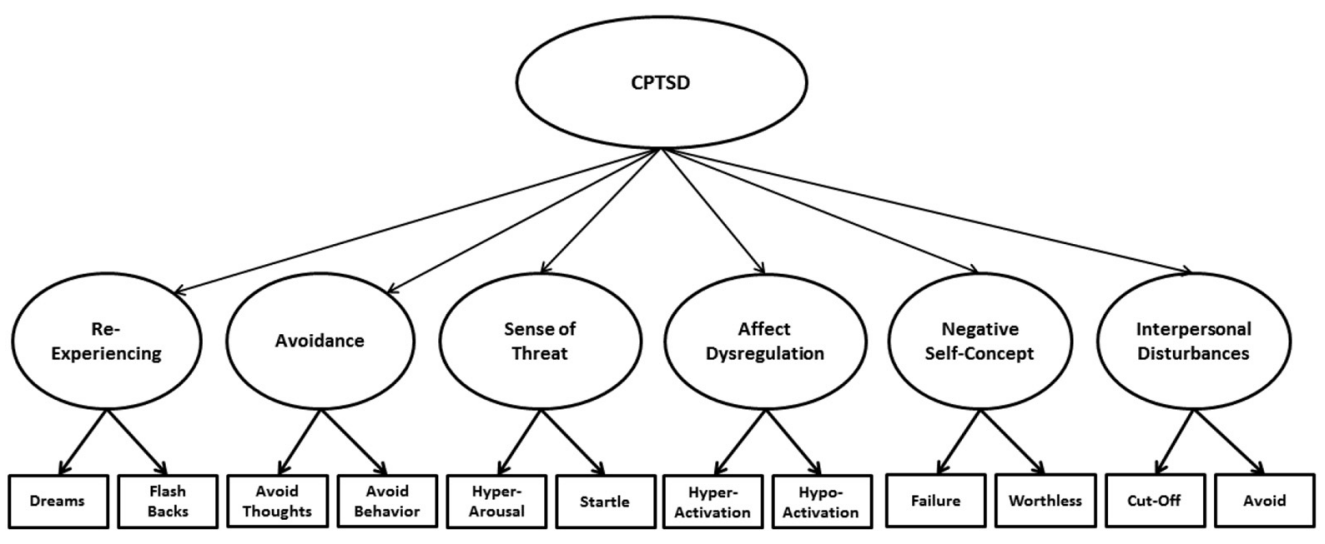

CPTSD Model 3: Two Factor Higher Order Model

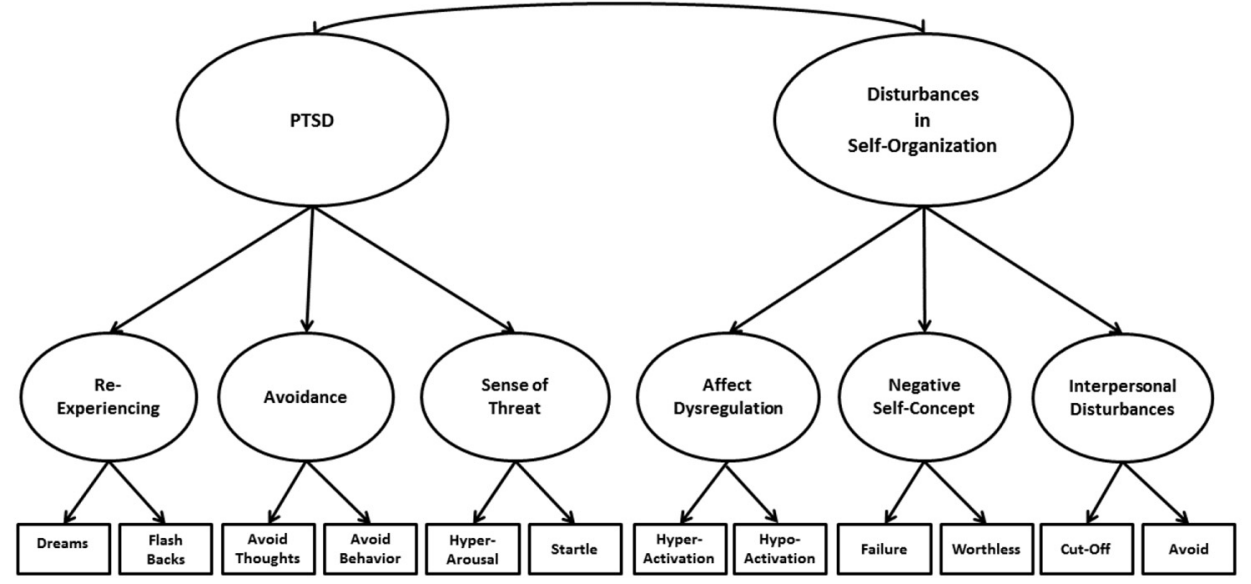

Fig. 1. Three theoretical models of CPTSD factor structure.

PTSD are higher than CPTSD while the reverse relationship obtains in trauma specialty clinics.

\subsection{Correlates}

Several studies have provided information comparing CPTSD and PTSD by functional status, type of trauma, and sociodemographic and symptom characteristics, offering some insight into differential risk factors and outcomes.

\subsubsection{Functional impairment}

Findings regarding differences in functional impairment have been consistent. Impairment has been found to be higher in the CPTSD class as compared to the PTSD class in all studies that evaluated it (Cloitre et al., 2013; Cloitre et al., 2014; Perkonigg et al., 2016). These data support the distinction between CPTSD and PTSD in regards to differences in severity of functional impairment, which may have implications for the nature and duration of treatment. 


\subsubsection{Childhood and chronic interpersonal trauma}

Consistent with the findings concerning complex PTSD in the DSMIV field trials, childhood interpersonal trauma has been reported at significantly higher rates among those fulfilling the CPTSD as compared to the PTSD symptom profile. This includes samples with childhood sexual and physical abuse (Cloitre et al., 2013; Cloitre et al., 2014; Karatzias et al., 2016), survivors of childhood institutional abuse (Knefel, Garvert, Cloitre, \& Lueger-Schuster, 2015), and those abducted as children for soldiering (Murphy, Elklit, Dokkedahl, \& Shevlin, 2016). Further support for the relationship between childhood trauma and CPTSD comes from a study of a nationally representative sample of Danes (Hyland et al., 2017), which found that cumulative exposure to multiple forms of childhood interpersonal violence created risk of CPTSD as compared to PTSD classification in a dose-response fashion. The presence of one type of childhood interpersonal violence produced twice the risk of CPTSD relative to PTSD and that risk substantially increased with every additional event type.

CPTSD profiles have also been observed in samples reporting sustained chronic trauma in adulthood, including prisoners of war and refugees (Nickerson et al., 2016; Palic et al., 2016). However, the presence of a CPTSD profile has emerged in samples comprised of single-incident adult traumas such as sexual assault, physical assault, and loss of a child, albeit at lower rates than PTSD (Elklit, Hyland, \& Shevlin, 2014). The proportion of the samples falling into the CPTSD profile in the study by Elklit et al. (2014) ranged from $10 \%$ to $21 \%$ as compared $25 \%$ to $43 \%$ for the PTSD profile.

These studies demonstrate that while those who experience childhood and other chronic forms of trauma are at greater risk for CPTSD than PTSD, it also the case that a smaller proportion develop PTSD and not CPTSD (Cloitre et al., 2013; Cloitre et al., 2014; Karatzias et al., 2016; Knefel et al., 2015; Hyland et al., 2017; Hyland et al., 2017; Murphy et al., 2016; Nickerson et al., 2016; Palic et al., 2016). Conversely, some individuals with adult-onset single traumas develop CPTSD (Elklit et al., 2014). Viewing trauma history as a risk factor rather than as a requirement for the disorders aligns with the emerging data. Such findings are not remarkable considering the potential influences of personal and environmental risk and resiliency factors. For example, the presence of CPTSD in an individual with a single adult onset trauma may be due to the severity of the event (e.g., gang rape, witnessing the violent death of one's child) as well as personal vulnerabilities (e.g., genetic predisposition) and/or environmental factors (social criticism). Conversely, a person with a history of childhood sexual abuse might develop PTSD rather than CPTSD due to the presence of protective factors (e.g., personal resiliency, supportive family system). Given that we treat symptoms not history, it is important that diagnosis is only guided, and not constrained, by the latter.

\subsubsection{Sociodemographic and symptom characteristics}

There are sociodemographic and symptom-related correlates which distinguish CPTSD and PTSD. Individuals with CPTSD relative to PTSD profiles are more likely to be unemployed, less likely to be married and more likely to live alone (Karatzias et al., 2016). In addition, the CPTSD but not the PTSD profile has been associated with minority status, lower education and lower self-reported SES (Perkonigg et al., 2016). It should be noted that the above studies were based on cross-sectional data and it is not known whether these characteristics are causes or consequences (or both) of CPTSD. Lastly, there is some evidence that, relative to PTSD, CPTSD is associated with greater psychopathology including a greater number of co-morbid disorders (Perkonigg et al., 2016) and greater severity of comorbid symptoms (Elklit et al., 2014; Murphy et al., 2016).

The data on the role of gender are inconsistent. Some studies have found that being female increases risk for both PTSD and CPTSD (Hyland et al., 2017; Perkonigg et al., 2016) while two studies have not found an effect of gender on risk for either diagnosis (Cloitre et al., 2013; Wolf et al., 2015). Results are mixed regarding whether there is gender-related risk for one disorder over another. Some studies have found that female gender is associated with greater risk for CPTSD than PTSD (Knefel et al., 2015; Perkonigg et al., 2016; Sachser et al., 2016), and one has found the reverse (Hyland et al., 2017). But the majority of studies have found no gender difference between the two disorders (Cloitre et al., 2013; Hyland et al., 2017; Karatzias et al., 2016; Murphy et al., 2016; Wolf et al., 2015). Differences in findings may be related to the nature of the samples. For example, clinical samples, which are typically comprised of self-referred individuals, may represent those suffering at the extreme end of the symptom continuum, where gender differences may no longer play an important role. Similarly, there may be certain types of extreme experiences (e.g., being abducted into child soldiering), or highly unfavorable environments (e.g., poverty, neglect) where the effect of gender relative to other factors no longer makes a significant contribution. Studies with larger samples that vary in type of trauma exposure, environmental risks, and protective factors are necessary to determine how gender may predispose to PTSD and CPTSD.

\subsection{Clinical utility}

Lastly, accuracy in differential diagnosis seems to be improved with the introduction of ICD-11 CPTSD. In the vignette study of 1738 mental health professionals by, Keeley, Reed, Roberts, Evans, Robles, et al. (2016) described above, a pair of vignettes presented to clinicians included one with a complex post-traumatic symptom presentation that incorporated the symptoms described by ICD-10 EPCACE and ICD-11 CPTSD and one with only the symptoms of re-experiencing, avoidance and arousal, describing PTSD. Accurate recognition of the complex presentation was substantially higher using the ICD-11 CPTSD than the EPCACE guideline.

\subsection{Summary}

The distinction between PTSD and CPTSD has been supported in several latent class and latent profile analyses demonstrating that the characteristics associated with each disorder are associated with different groups of individuals. The difference between the two disorders seems readily observable to clinicians and accuracy in differential diagnosis is high in a vignette study. Tests of the factor structure of CPTSD symptoms have supported a model that includes two higherorder correlated factors (PTSD and DSO), each measured by 3 firstorder symptom clusters. Type of trauma should be conceived of as a risk factor and does not determine whether the person will present with a PTSD or CPTSD profile.

\section{Discussion}

The proposed ICD-11 diagnostic requirements for PTSD and CPTSD were the result of an attempt to develop a new international classification for stress- and trauma-related disorders that enhances the clinical utility and applicability of the diagnoses worldwide. In the formulations of both PTSD and CPTSD, the ICD-11 proposals attempt to simplify the definitions, reduce the number of symptoms, and clarify the differences as well as the relationship between the two disorders. Not surprisingly, the proposals have attracted discussion. One concern is that the lack of harmonization between ICD-11 and DSM- 5 will be confusing to persons who receive a PTSD diagnosis, clinicians, researchers, and others (Bisson, 2013). We are sympathetic to this argument but note that ICD is far more widely used worldwide than DSM (Reed, Correia, Esparza, Saxena, \& Maj, 2011). Moreover, there are costs, described in more detail below, involved in retaining an imperfect diagnostic structure just because it is in common use.

It has also been argued (Vermetten, Baker, Jetly, \& McFarlane, 2016) that divergent diagnostic systems should not produce significantly different prevalence rates or high levels of discordance. The authors suggest that the ICD-11 proposals are incompatible with the 
advancement of consensus within the field. It seems to us, however, that prevalence rates must depend on an adequate, scientifically-based formulation of the diagnosis, not the other way round. At present PTSD is, and likely will remain, a much debated diagnosis (Brewin, 2003; Hoge et al., 2016; Rosen \& Lilienfeld, 2008; Spitzer et al., 2007), a situation which does not argue for remaining loyal to the existing formulation at all costs. It seems to us appropriate that if our understanding of the condition changes, prevalence rates might follow suit.

Likewise, an attempt to avoid any discordant diagnoses runs the risk that we overlook impaired individuals who are not currently receiving a diagnosis under ICD-10, DSM-IV, or DSM-5. The ICD-11 proposals allow us to independently evaluate the reach of these diagnostic systems and, conceivably, to improve our identification of affected individuals. Given the relatively recent introduction of the diagnosis, it is not surprising that a universally accepted empirical foundation is not yet available for PTSD. We therefore believe it is healthy that alternative diagnostic formulations compete to see which are most clinically useful and able to contribute toward improving the international recognition and treatment of disease.

The lack of complete diagnostic agreement among different systems highlights another important question: whether those PTSD cases that DSM-IV or DSM-5 recognize but that ICD-11 does not would nevertheless meet diagnostic requirements for other conditions, such as major depressive disorder, and would therefore still potentially have access to appropriate treatment. This appears plausible given the very large number of combinations of qualifying symptoms under DSM-IV and DSM-5. Psychotherapy for PTSD shows substantial efficacy but the average effect size of 1.43 for pre- versus post-treatment comparisons indicates that there is plenty of room for improvement, with most patients continuing to have substantial residual symptoms posttreatment (Bradley, Greene, Russ, Dutra, \& Westen, 2005; Cusack et al., 2016). In the future it will be important to determine whether outcomes can be improved by targeting comorbid diagnoses as well as, or in some cases instead of, providing trauma-focussed treatment (Rahman et al., 2016).

One other possible implication of the differences in the DSM-5 and ICD-11 descriptions of PTSD concerns how people identified by each diagnosis respond to evidence-based treatments. Most international treatment guidelines recommend trauma-focused cognitive behavior therapy (Institute of Medicine, 2008; National Institute of Clinical Excellence, 2005). These recommendations emerge from many controlled trials that have focused on reliving one's trauma memories. It has been noted by some critics that the move in DSM- 5 to shift the diagnosis beyond the fear response to encompass negative moods more generally may reduce the applicability of this treatment for people identified as suffering PTSD (Hoge et al., 2016). In contrast, it is possible that the ICD-11 requirement of re-experiencing memories will increase the applicability of exposure-based therapy for these individuals.

One of the features of ICD-11 PTSD is the emphasis on re-experiencing in the present. This aspect is not fully captured by existing instruments, which generally make reference only to 'flashbacks'. There has been considerable uncertainty in how to understand this term, with DSM-5 and ICD-11 clarifying for the first time that it is most usefully used to refer to a continuum from severe to mild re-experiencing in the present. Field trials indicate that education about this change is necessary, and more detailed research into the nature of this core re-experiencing symptom and how best to measure it is urgently needed (Brewin, 2015). Among the outstanding issues are whether re-experiencing in the present is a universal aspect of PTSD or whether some trauma types (e.g., childhood sexual abuse) are associated with reliving that differs in intensity, frequency, sensory-perceptual, or other characteristics.

An important next step is to complete the development and testing of interview and self-report measures of the two ICD-11 diagnoses. Measures currently undergoing development include the International Trauma Interview and International Trauma Questionnaire, formerly known as the ICD Trauma Interview (Powers et al., 2017) and ICD Trauma Questionnaire (Hyland et al., 2017; Karatzias et al., 2016; Murphy et al., 2016). With these measures particular attention is being paid to finalizing the re-experiencing items and the number of symptoms that will describe the CPTSD profile. The symptoms identified in the three clusters of PTSD (usually two per cluster) have been selected from two decades of research in which re-experiencing, avoidance and hyperarousal have been investigated. This is not the case with the symptoms describing disturbances in self-organization, the selection of which has been based on the research regarding the DESNOS diagnosis. In particular, the role of dissociation needs to be re-considered. Expressed as a type of re-experiencing, dissociation may fall under the PTSD diagnosis. However, when expressed as a type of emotion dysregulation, it might be considered to align with the DSO symptom profile.

Exposure to stressors that are chronic, prolonged, and difficult or impossible to escape from, has been found to be a risk factor rather than an inevitable precursor of CPTSD. It will be important to determine whether chronic traumas that occur in adulthood carry equal risk for CPTSD as those that occur in childhood. Different aspects of CPTSD may be more salient than others depending on the type of stressor. For example, uncontrollable anger tends to have relatively low endorsement as part of the affect dysregulation cluster among adults with childhood sexual and/or physical abuse (Cloitre et al., 2014), but much higher endorsement among those who were exposed to armed conflict and abducted into child soldiering (Murphy et al., 2016). This will need further investigation as research moves toward refining the number and content of the items in the DSO cluster.

Some have suggested that CPTSD be considered a subtype of PTSD rather than an independent diagnosis because CPTSD includes the three PTSD symptom clusters. There are both practical (clinical utility) and conceptual reasons not to do this. Research on clinicians indicates that they tend not to look at or use subtype information (Reed, 2010). Given that CPTSD may be as prevalent as PTSD in some settings, the salience of the diagnosis being considered by the clinician is important. From a conceptual perspective, it is quite possible that the PTSD symptom clusters among those who have CPTSD may differ in their nature, frequency, and intensity. They may contribute less or differently to functional impairment in the context of other symptoms such affect dysregulation or negative self-concept, relative to their expression in PTSD. Defining CPTSD as a disorder separate and distinct from PTSD will support a conceptualization of the disorder where equal attention is more likely to be given to both DSO and PTSD symptoms in terms of research, assessment, and treatment development and planning.

We hope the diagnosis of CPTSD will reduce diagnostic comorbidity relative to DSM-5. The symptoms proposed in the DSO clusters of CPTSD are frequently observed among those who have experienced chronic trauma but the recognition of such symptoms has been available only through the inclusion of an additional diagnosis. For example, affective dysregulation (e.g., emotional reactivity), negative self-concept (e.g., low self-worth) and interpersonal problems (e.g., fear and avoidance of relationships) have typically been captured by the addition of Borderline Personality Disorder, Dysthymia or Major Depressive Disorder and Social Phobia respectively. The inclusion of such symptoms into the CPTSD profile and symptom clusters is supported by nine latent profile/class analyses and four factor analytic studies. A reduction in comorbidity may be achievable if the symptoms which led to the inclusion of additional "comorbid" diagnoses in order to be accounted for are now identified within the CPTSD diagnosis. In this approach, diagnosis would require an assessment of the relatedness of symptoms to a traumatic event (e.g., symptoms emerge or worsen after event) and use of hierarchical procedures whereby a symptom could only be counted once and contribute once to a single diagnosis. The benefits of limiting diagnosis to one rather than a multiplicity of disorders include simplification in assessment, potential reduction of stigma for the patient, and streamlined treatment. 
An important outstanding issue is the impact of developmental issues on the presentation of PTSD and CPTSD symptoms. The data so far are interesting in that distinct PTSD and CPTSD groups have been identified. Moreover, differences in the prevalence rates of PTSD among children and adolescents according to ICD-11 and DSM-IV/5 appear to be less discrepant than among adult samples, and ICD-11 appears to be uniquely identifying more cases than DSM-IV/5 (Danzi \& La Greca, 2016; Haravuori et al., 2016). This may reflect the consensus that PTSD is likely being underdiagnosed in children, at least in part because of the difficulty in identifying avoidance and numbing (Scheeringa, Zeanah, \& Cohen, 2011). The absence of numbing symptoms in ICD-11 PTSD may be an advantage in this respect. However, much remains to be learned about how PTSD should be defined and measured in children of different ages.

In conclusion, we believe it is reasonable to diagnose PTSD more simply and to distinguish presentations corresponding to PTSD and CPTSD. Research on four continents has shown that alternative conceptualizations of PTSD are viable in that they identify some individuals, particularly children and adolescents, with approximately equal levels of impairment who are missed by DSM-IV or DSM-5. Moreover, having another formulation of PTSD has generated a lot of research that would otherwise not have been done and that will inform future diagnostic developments. Establishing the value of diagnostic systems is a project without a clear endpoint; one goal is to determine whether the development of different treatment plans (differences in type and number of interventions and duration of treatment) tailored to the symptom profiles described by each disorder may lead to better patient outcomes as well as more efficient use of limited clinician and system resources. We believe that the ICD-11 proposals will assist the identification and treatment of people affected by trauma worldwide.

\section{Author disclosure}

Chris Brewin and Marylène Cloitre wrote the first draft of the manuscript. Philip Hyland and Mark Shevlin contributed statistical advice. All authors contributed to and have approved the final manuscript.

C.R. Brewin, M. Cloitre, A. Maercker, R.A. Bryant, A. Humayan, L.M. Jones, A. Kagee, C. Rousseau, D.J. Somasundaram, S.C. Wessely and Y. Suzuki are members of the WHO ICD-11 Working Group on the Classification of Disorders Specifically Associated with Stress, reporting to the WHO International Advisory Group for the Revision of ICD-10 Mental and Behavioural Disorders. G.M. Reed and M. van Ommeren are members of the WHO Secretariat, Department of Mental Health and Substance Abuse. The views expressed in this article are those of the authors and do not represent the official policies or positions of the International Advisory Group or the WHO.

Appendix A. Studies reporting prevalence, comorbidity, and validity of the proposed ICD-11 PTSD $\operatorname{diagnosis}^{\mathrm{a}}(n=17)$

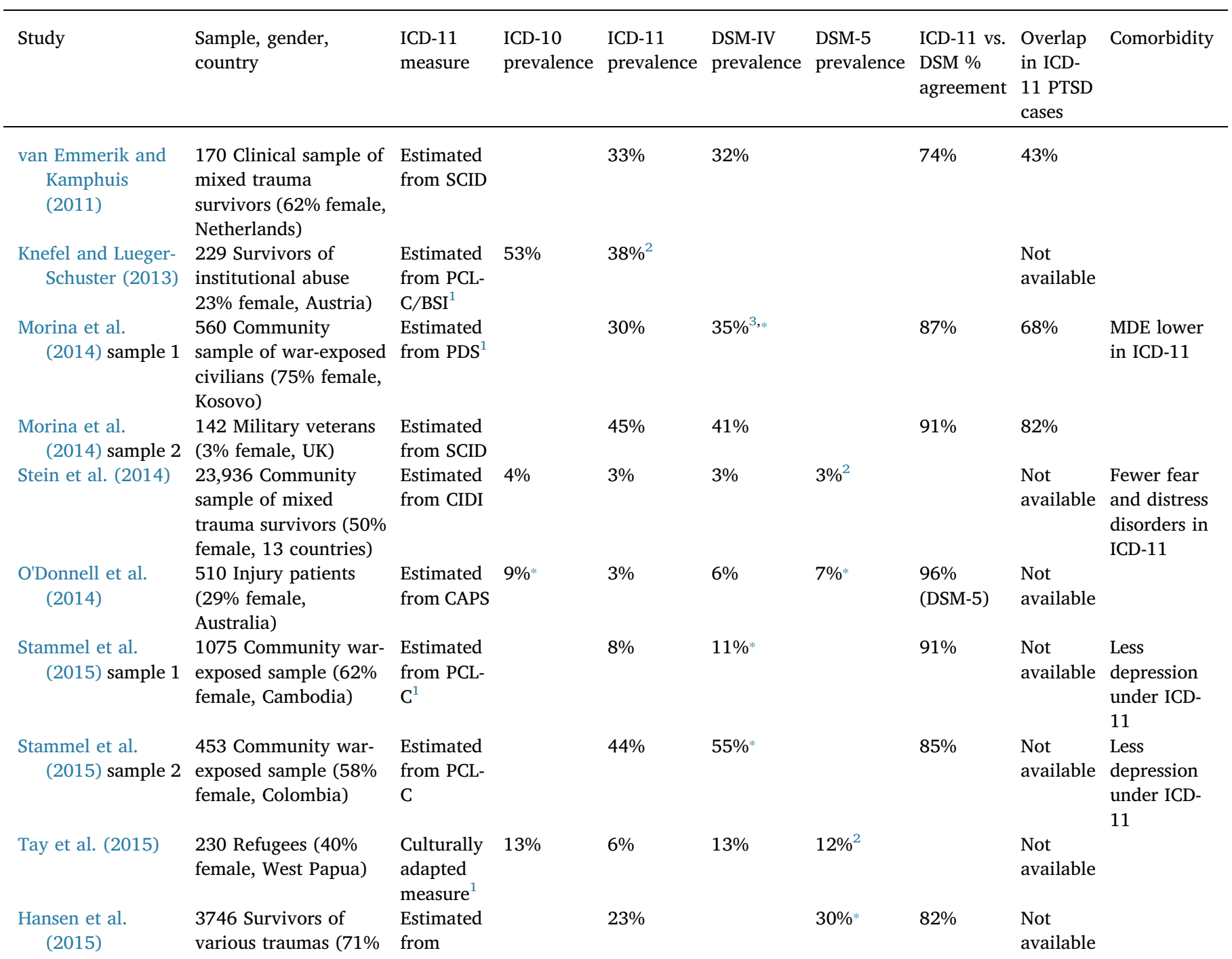




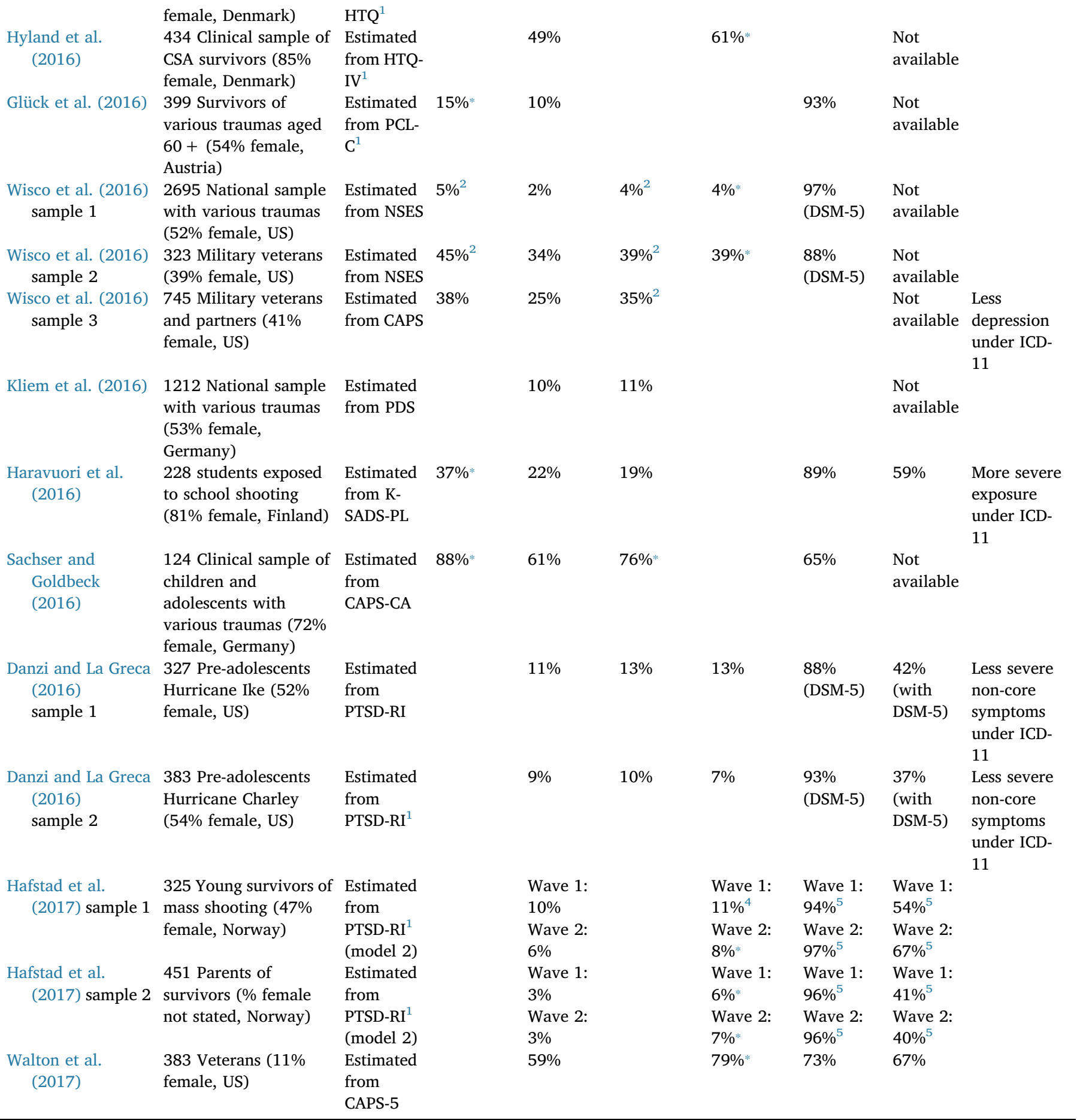

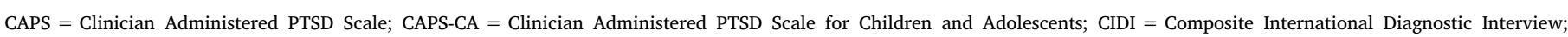

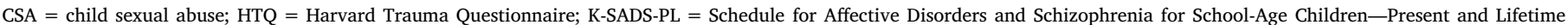

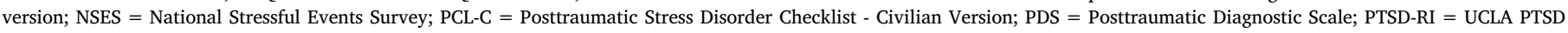
Reaction Index; SCID = Structured Clinical Interview for DSM-IV.

${ }^{\text {a }}$ PTSD cases include an unspecified number of CPTSD cases.

${ }^{1}$ Impairment not measured.

${ }^{2}$ Data for test of correlated proportions not provided.

${ }^{3}$ Data recalculated using test of correlated proportions.

${ }^{4}$ See Corrigendum to article.

${ }^{5}$ Additional data supplied by the authors.

* Statistically significant difference to ICD-11 prevalence. 
Appendix B. Studies completing latent profile/class analyses to assess CPTSD versus PTSD groups $(n=10)$

\begin{tabular}{|c|c|c|c|c|c|c|}
\hline Study & Sample, gender, country & $\begin{array}{l}\text { PTSD } \\
\text { symptom } \\
\text { measure }\end{array}$ & $\begin{array}{l}\text { DSO } \\
\text { symptom } \\
\text { measure }\end{array}$ & Result & $\begin{array}{l}\text { Class differences by trauma } \\
\text { type }\end{array}$ & $\begin{array}{l}\text { Class differences by } \\
\text { impairment, demographics } \\
\text { and symptoms }\end{array}$ \\
\hline $\begin{array}{l}\text { Cloitre } \\
\text { et al. } \\
\text { (2014) }\end{array}$ & $\begin{array}{l}310 \text { Treatment-seeking } \\
\text { survivors of CPA and/or } \\
\text { CSA (100\% female, USA) }\end{array}$ & CAPS-IV & $\begin{array}{l}\text { BSI } \\
\text { SCID-IV } \\
\text { for BPD }\end{array}$ & $\begin{array}{l}\text { 4-class solution } \\
\text { with distinct } \\
\text { PTSD/CPTSD/BPD } \\
\text { groups }\end{array}$ & $\begin{array}{l}\text { CPTSD > BPD: Any CSA } \\
\text { CPTSD > Low symptoms } \\
\text { group: Any CSA } \\
\text { No differences across CPTSD, } \\
\text { PTSD and BPD on any CA, any } \\
\text { adult IPV, cumulative lifetime } \\
\text { trauma }\end{array}$ & $\begin{array}{l}\text { Impairment in CPTSD and } \\
\text { BPD equivalent and both } \\
\text { greater than PTSD }\end{array}$ \\
\hline $\begin{array}{l}\text { Elklit et al. } \\
\text { (2014) } \\
\text { sample } \\
1\end{array}$ & $\begin{array}{l}449 \text { Clinical sample of } \\
\text { sexual assault survivors } \\
\text { (98\% female, Denmark) }\end{array}$ & HTQ & TSC & $\begin{array}{l}\text { 3-class solution } \\
\text { with distinct } \\
\text { PTSD/CPTSD } \\
\text { groups }\end{array}$ & $\begin{array}{l}\text { Sample defined by trauma } \\
\text { type: } 13 \% \text { in CPTSD class } \\
34 \% \text { with PTSD profile } \\
53 \% \text { in Low Symptoms class }\end{array}$ & Not available \\
\hline $\begin{array}{l}\text { Elklit et al. } \\
\text { (2014) } \\
\text { sample } \\
2\end{array}$ & $\begin{array}{l}214 \text { Clinical sample of } \\
\text { physical assault survivors } \\
\text { (27\% female, Denmark) }\end{array}$ & HTQ & TSC & $\begin{array}{l}\text { 3-class solution } \\
\text { with distinct } \\
\text { PTSD/CPTSD } \\
\text { groups }\end{array}$ & $\begin{array}{l}\text { Sample defined by trauma } \\
\text { type: } \\
21 \% \text { in CPTSD class } \\
43 \% \text { with PTSD profile } \\
36 \% \text { in Low Symptoms class }\end{array}$ & Not available \\
\hline $\begin{array}{l}\text { Elklit et al. } \\
\text { (2014) } \\
\text { sample } \\
3\end{array}$ & $\begin{array}{l}608 \text { Community sample } \\
\text { of parents who had lost a } \\
\text { child ( } 58 \% \text { female, } \\
\text { Denmark) }\end{array}$ & HTQ & TSC & $\begin{array}{l}\text { 3-class solution } \\
\text { with distinct } \\
\text { PTSD/CPTSD } \\
\text { groups }\end{array}$ & $\begin{array}{l}\text { Sample defined by trauma } \\
\text { type: } 10 \% \text { in CPTSD class } \\
25 \% \text { with PTSD profile } \\
64 \% \text { in Low Symptoms class }\end{array}$ & Not available \\
\hline $\begin{array}{l}\text { Wolf et al. } \\
\text { (2015) } \\
\text { sample } \\
2\end{array}$ & $\begin{array}{l}323 \text { Military veterans } \\
\text { (39\% female, USA) }\end{array}$ & $\begin{array}{l}\text { NSES } \\
\text { DSM-5 } \\
\text { items }\end{array}$ & $\begin{array}{l}\text { NCSES } \\
\text { DSM-5 } \\
\text { CPTSD } \\
\text { items }\end{array}$ & $\begin{array}{l}\text { 3- and 4-class } \\
\text { solutions with } \\
\text { distinct PTSD/ } \\
\text { CPTSD using LPA } \\
\text { but not with FMM }\end{array}$ & $\begin{array}{l}\text { CPTSD = PTSD: cumulative } \\
\text { lifetime sexual assault, } \\
\text { cumulative lifetime physical } \\
\text { assault }\end{array}$ & $\begin{array}{l}\text { Impairment data not } \\
\text { available } \\
\text { No differences by gender, } \\
\text { age, minority status }\end{array}$ \\
\hline $\begin{array}{l}\text { Knefel } \\
\qquad \text { et al. } \\
\text { (2015) }\end{array}$ & $\begin{array}{l}229 \text { Community sample } \\
\text { of institutional abuse } \\
\text { survivors ( } 23 \% \text { female, } \\
\text { Austria) }\end{array}$ & PCL-C & BSI & $\begin{array}{l}\text { 4-class solution } \\
\text { with distinct } \\
\text { PTSD/CPTSD } \\
\text { groups }\end{array}$ & Not available & $\begin{array}{l}\text { Impairment data not } \\
\text { available } \\
\text { Female gender risk factor } \\
\text { for CPTSD } \\
\text { No gender differences in risk } \\
\text { for PTSD }\end{array}$ \\
\hline $\begin{array}{l}\text { Perkonigg } \\
\text { et al. } \\
\text { (2016) }\end{array}$ & $\begin{array}{l}3021 \text { Community sample } \\
\text { of young adult survivors } \\
\text { of interpersonal violence } \\
\text { ( } 42 \% \text { female, Germany) }\end{array}$ & $\begin{array}{l}\text { M-CIDI- } \\
\text { DSM-IV }\end{array}$ & SCL-90-R & $\begin{array}{l}\text { 4-class solution } \\
\text { with distinct } \\
\text { PTSD/CPTSD } \\
\text { groups }\end{array}$ & Not available & $\begin{array}{l}\text { Greater impairment in } \\
\text { CPTSD than PTSD } \\
\text { Female gender risk for } \\
\text { CPTSD and PTSD } \\
\text { CPTSD (but not PTSD) } \\
\text { associated with younger } \\
\text { age, lower education, living } \\
\text { alone,lower SES CPTSD } \\
\text { more comorbid diagnoses } \\
\text { than PTSD }\end{array}$ \\
\hline Palic et al. & 820 Clinical and & PTSD-I & SIDS-R/ & 4- and 5-class & In Denmark CSA most & CPTSD highest impairment \\
\hline
\end{tabular}


(2016) community sample exposed to prolonged interpersonal violence (45\% female, Denmark, Israel, Bosnia)

Karatzias 193 Clinical et al. exposed to mixed

(2016) interpersonal violence (65\% female, Scotland)

ICD-TQ ICD-TQ

ICD-TQ 2-class solution with distinct PTSD/CPTSD groups distinct PTSD/ CPTSD groups Israel CSA and POWs, plus in
Int Bosnia refugees, most frequently in CPTSD group

CPTSD > PTSD: CSA, CPA, neglect, emotional abuse, emotional neglect, cumulative childhood abuse trauma, cumulative lifespan trauma

\begin{tabular}{|c|c|c|c|c|}
\hline $\begin{array}{l}\text { Iurphy } \\
\text { et al. } \\
\text { (2016) }\end{array}$ & $\begin{array}{l}314 \text { Young adults (child } \\
\text { soldiers) ( } 51 \% \text { female, } \\
\text { Uganda) }\end{array}$ & ICD-TQ & ICD-TQ & $\begin{array}{l}\text { 3-class solution } \\
\text { with distinct } \\
\text { PTSD/CPTSD }\end{array}$ \\
\hline
\end{tabular}

PTSD and CPTSD predicted by child soldier status. CPTSD associated with higher levels of war exposure compared to other two groups

\section{Greater impairment in CPTSD than PTSD No gender differences} CPTSD greater likelihood ofunemployment, being unmarried, living alone, taking medication Impairment data not available

No gender differences CPTSD had greater anxiety, depression, somatic symptoms, \& conduct problems than other two groups

\begin{tabular}{|c|c|c|c|c|}
\hline $\begin{array}{l}\text { Sachser } \\
\quad \text { et al. } \\
(2016)\end{array}$ & $\begin{array}{l}155 \text { Clinical sample of } \\
\text { children and adolescents } \\
\text { ( } 72 \% \text { female, Germany) }\end{array}$ & CAPS-CA & CPCI & $\begin{array}{l}\text { 2-class solution } \\
\text { with distinct } \\
\text { PTSD/CPTSD } \\
\text { groups }\end{array}$ \\
\hline
\end{tabular}

\section{CPTSD group had more Impairment data not} interpersonal violence trauma available Female gender higher in CPTSD; male gender higher in PTSD group No differences in age, living with parent, or parental education

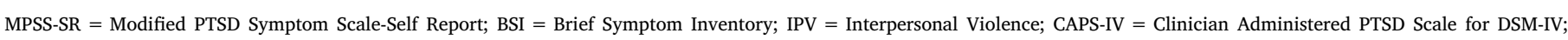

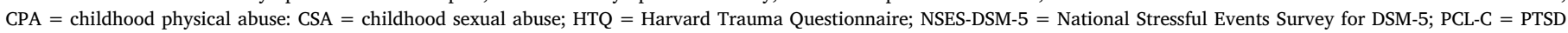

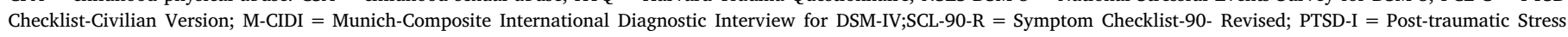

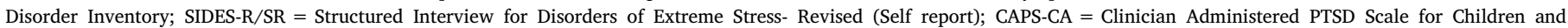

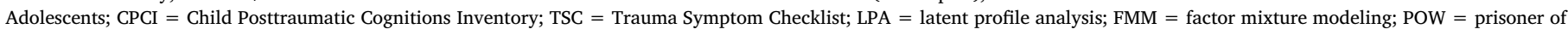
war; ICD-TQ = ICD-11 Trauma Questionnaire.

\section{References}

American Psychiatric Association (1980). Diagnostic and statistical manual of mental disorders (3rd ed.). Washington, DC: American Psychiatric Association.

American Psychiatric Association (2000). Diagnostic and statistical manual of mental disorders (4th ed.). Washington, DC: American Psychiatric Association Text revision.

American Psychiatric Association (2013). Diagnostic and statistical manual of mental disorders (5th ed.). Washington, DC: American Psychiatric Association.

Armour, C., Fried, E. I., Deserno, M. K., Tsai, J., \& Pietrzak, R. H. (2017). A network analysis of DSM-5 posttraumatic stress disorder symptoms and correlates in US military veterans. Journal of Anxiety Disorders, 45, 49-59. http://dx.doi.org/10.1016/ j.janxdis.2016.11.008.

Bisson, J. I. (2013). What happened to harmonization of the PTSD diagnosis? The divergence of ICD-11 and DSM-5. Epidemiology and Psychiatric Sciences, 22, 205-207. http://dx.doi.org/10.1017/s2045796013000164.

Bradley, R., Greene, J., Russ, E., Dutra, L., \& Westen, D. (2005). A multidimensional metaanalysis of psychotherapy for PTSD. American Journal of Psychiatry, 162, 214-227. http://dx.doi.org/10.1176/appi.ajp.162.2.214.

Brady, K. T., Killeen, T. K., Brewerton, T., \& Lucerini, S. (2000). Comorbidity of psychiatric disorders and posttraumatic stress disorder. The Journal of Clinical Psychiatry, 61, 22-32.

Brewin, C. R. (2003). Posttraumatic stress disorder: Malady or myth? New Haven, CT: Yale University Press.

Brewin, C. R. (2013). "I wouldn't start from here"-an alternative perspective on PTSD from the ICD-11: Comment on Friedman (2013). Journal of Traumatic Stress, 26, 557-559. http://dx.doi.org/10.1002/jts.21843.

Brewin, C. R. (2015). Re-experiencing traumatic events in PTSD: New avenues in research on intrusive memories and flashbacks. European Journal of Psychotraumatology, 6. http://dx.doi.org/10.3402/ejpt.v6.27180.

Brewin, C. R., Fuchkan, N., Huntley, Z., Robertson, M., Thompson, M., Scragg, P., ... Ehlers, A. (2010). Outreach and screening following the 2005 London bombings: Usage and outcomes. Psychological Medicine, 40, 2049-2057. http://dx.doi.org/10. 1017/s0033291710000206.

Brewin, C. R., Gregory, J. D., Lipton, M., \& Burgess, N. (2010). Intrusive images in psychological disorders: Characteristics, neural mechanisms, and treatment implications. Psychological Review, 117, 210-232. http://dx.doi.org/10.1037/a0018113.

Brewin, C. R., Lanius, R. A., Novac, A., Schnyder, U., \& Galea, S. (2009). Reformulating PTSD for DSM-V: Life after criterion A. Journal of Traumatic Stress, 22, 366-373. http://dx.doi.org/10.1002/jts.20443.

Broman-Fulks, J. J., Ruggiero, K. J., Green, B. A., Kilpatrick, D. G., Danielson, C. K. Resnick, H. S., \& Saunders, B. E. (2006). Taxometric investigation of PTSD: data from two nationally representative samples. Behavior Therapy, 37, 364-380. http://dx.doi. org/10.1016/j.beth.2006.02.006.

Broman-Fulks, J. J., Ruggiero, K. J., Green, B. A., Smith, D. W., Hanson, R. F., Kilpatrick, D. G., \& Saunders, B. E. (2009). The latent structure of posttraumatic stress disorder among adolescents. Journal of Traumatic Stress, 22, 146-152. http://dx.doi.org/10. 1002/jts. 20399.

Bryant, R. A., Creamer, M., O'Donnell, M., Forbes, D., McFarlane, A. C., Silove, D., \& Hadzi-Pavlovic, D. (2017). Acute and chronic posttraumatic stress symptoms in the emergence of posttraumatic stress disorder: A network analysis. JAMA Psychiatry, 74, 135-142. http://dx.doi.org/10.1001/jamapsychiatry.2016.3470.

Bryant, R. A., O'Donnell, M. L., Creamer, M., McFarlane, A. C., \& Silove, D. (2011). Posttraumatic intrusive symptoms across psychiatric disorders. Journal of Psychiatric Research, 45, 842-847. http://dx.doi.org/10.1016/j.jpsychires.2010.11.012.

Byllesby, B. M., Durham, T. A., Forbes, D., Armour, C., \& Elhai, J. D. (2016). An investigation of PTSD's core dimensions and relations with anxiety and depression. Psychological Trauma, 8, 214-217. http://dx.doi.org/10.1037/tra0000081.

Cloitre, M., Courtois, C. A., Charuvastra, A., Carapezza, R., Stolbach, B. C., \& Green, B. L. (2011). Treatment of complex PTSD: Results of the ISTSS expert clinician survey on best practices. Journal of Traumatic Stress, 24, 615-627. http://dx.doi.org/10.1002/ jts. 20697.

Cloitre, M., Garvert, D. W., Brewin, C. R., Bryant, R. A., \& Maercker, A. (2013). Evidence for proposed ICD-11 PTSD and complex PTSD: A latent profile analysis. European Journal of Psychotraumatology, 4. http://dx.doi.org/10.3402/ejpt.v4i0.20706.

Cloitre, M., Garvert, D. W., Weiss, B., Carlson, E. B., \& Bryant, R. A. (2014). Distinguishing PTSD, complex PTSD, and borderline personality disorder: A latent class analysis. European Journal of Psychotraumatology, 5. http://dx.doi.org/10.3402/ejpt.v5.25097.

Cloitre, M., Roberts, N. P., Bisson, J. I., \& Brewin, C. R. (2015). The international trauma questionnaire. (Unpublished Measure).

Contractor, A. A., Durham, T. A., Brennan, J. A., Armour, C., Wutrick, H. R., Frueh, B. C., \& Elhai, J. D. (2014). DSM-5 PTSD's symptom dimensions and relations with major depression's symptom dimensions in a primary care sample. Psychiatry Research, 215, 146-153. http://dx.doi.org/10.1016/j.psychres.2013.10.015.

Cusack, K., Jonas, D. E., Forneris, C. A., Wines, C., Sonis, J., Middleton, J. C., ... Gaynes, B. N. (2016). Psychological treatments for adults with posttraumatic stress disorder: A systematic review and meta-analysis. Clinical Psychology Review, 43, 128-141. http:// dx.doi.org/10.1016/j.cpr.2015.10.003. 
Danzi, B. A., \& La Greca, A. M. (2016). DSM-IV, DSM-5, and ICD-11: Identifying children with posttraumatic stress disorder after disasters. Journal of Child Psychology and Psychiatry, 57, 1444-1452. http://dx.doi.org/10.1111/jcpp.12631.

Davidson, J. R. T., \& Foa, E. B. (1991). Diagnostic issues in posttraumatic stress disorder considerations for the DSM-IV. Journal of Abnormal Psychology, 100, 346-355. http:// dx.doi.org/10.1037//0021-843x.100.3.346.

de Bont, P. A. J. M., van den Berg, D. P. G., van der Vleugel, B. M., de Roos, C., de Jongh, A., van der Gaag, M., \& van Minnen, A. (2015). Predictive validity of the Trauma Screening Questionnaire in detecting post-traumatic stress disorder in patients with psychotic disorders. The British Journal of Psychiatry, 206, 408-416. http://dx.doi. org/10.1192/bjp.bp.114.148486.

Durham, T. A., Elhai, J. D., Fine, T. H., Tamburrino, M., Cohen, G., Shirley, E., ... Calabrese, J. R. (2015). Posttraumatic stress disorder's dysphoria dimension and relations with generalized anxiety disorder symptoms. Psychiatry Research, 228, 150-155. http://dx.doi.org/10.1016/j.psychres.2015.04.034.

Ehlers, A., \& Clark, D. M. (2000). A cognitive model of posttraumatic stress disorder. Behaviour Research and Therapy, 38, 319-345. http://dx.doi.org/10.1016/S00057967(99)00123-0.

Ehlers, A., Gene-Cos, N., \& Perrin, S. (2009). Low recognition of post-traumatic stress disorder in primary care. London Journal of Primary Care, 2, 36-42.

Elhai, J. D., Grubaugh, A. L., Kashdan, T. B., \& Frueh, B. C. (2008). Empirical examination of a proposed refinement to DSM-IV posttraumatic stress disorder symptom criteria using the National Comorbidity Survey Replication data. The Journal of Clinical Psychiatry, 69, 597-602.

Elklit, A., Hyland, P., \& Shevlin, M. (2014). Evidence of symptom profiles consistent with posttraumatic stress disorder and complex posttraumatic stress disorder in different trauma samples. European Journal of Psychotraumatology, 5. http://dx.doi.org/10. 3402/ejpt.v5.24221.

First, M. B., Reed, G. M., Hyman, S. E., \& Saxena, S. (2015). The development of the ICD11 clinical descriptions and diagnostic guidelines for mental and behavioural disorders. World Psychiatry, 14, 82-90. http://dx.doi.org/10.1002/wps.20189.

Forbes, D., Haslam, N., Williams, B. J., \& Creamer, M. (2005). Testing the latent structure of posttraumatic stress disorder: A taxometric study of combat veterans. Journal of Traumatic Stress, 18, 647-656. http://dx.doi.org/10.1002/jis.20073.

Forbes, D., Lockwood, E., Creamer, M., Bryant, R. A., McFarlane, A. C., Silove, D., .. O'Donnell, M. (2015). Latent structure of the proposed ICD-11 post-traumatic stress disorder symptoms: Implications for the diagnostic algorithm. The British Journal of Psychiatry, 206, 245-251. http://dx.doi.org/10.1192/bjp.bp.114.150078.

Ford, J. D., Elhai, J. D., Ruggiero, K. J., \& Frueh, B. C. (2009). Refining posttraumatic stress disorder diagnosis: Evaluation of symptom criteria with the National Survey of Adolescents. The Journal of Clinical Psychiatry, 70, 748-755.

Friedman, M. J., Resick, P. A., Bryant, R. A., \& Brewin, C. R. (2011). Considering PTSD for DSM-V. Depression and Anxiety, 28, 750-769. http://dx.doi.org/10.1002/da.20767.

Galatzer-Levy, I. R., \& Bryant, R. A. (2013). 636,120 ways to have posttraumatic stress disorder. Perspectives on Psychological Science, 8, 651-662. http://dx.doi.org/10. 1177/1745691613504115.

Glück, T. M., Knefel, M., Tran, U. S., \& Lueger-Schuster, B. (2016). PTSD in ICD-10 and proposed ICD-11 in elderly with childhood trauma: Prevalence, factor structure, and symptom profiles. European Journal of Psychotraumatology, 7. http://dx.doi.org/10. 3402/ejpt.v7.29700.

Gootzeit, J., \& Markon, K. (2011). Factors of PTSD: Differential specificity and external correlates. Clinical Psychology Review, 31, 993-1003. http://dx.doi.org/10.1016/j. cpr.2011.06.005.

Grubaugh, A. L., Long, M. E., Elhai, J. D., Frueh, B. C., \& Magruder, K. M. (2010). An examination of the construct validity of posttraumatic stress disorder with veterans using a revised criterion set. Behaviour Research and Therapy, 48, 909-914. http://dx. doi.org/10.1016/j.brat.2010.05.019.

Hafstad, G. S., Dyb, G., Jensen, T. K., Steinberg, A. M., \& Pynoos, R. S. (2014). PTSD prevalence and symptom structure of DSM-5 criteria in adolescents and young adults surviving the 2011 shooting in Norway. Journal of Affective Disorders, 169, 40-46. http://dx.doi.org/10.1016/j.jad.2014.06.055.

Hafstad, G. S., Thoresen, S., Wentzel-Larsen, T., Maercker, A., \& Dyb, G. (2017). PTSD or not PTSD? Comparing the proposed ICD-11 and the DSM-5 PTSD criteria among young survivors of the 2011 Norway attacks and their parents. Psychological Medicine, 47, 1283-1291. http://dx.doi.org/10.1017/S0033291716002968.

Hansen, M., Hyland, P., Armour, C., Shevlin, M., \& Elklit, A. (2015). Less is more? Assessing the validity of the ICD-11 model of PTSD across multiple trauma samples. European Journal of Psychotraumatology, 6. http://dx. doi.org/10.3402/ejpt.v6.28766.

Haravuori, H., Kiviruusu, O., Suomalainen, L., \& Marttunen, M. (2016). An evaluation of ICD-11 posttraumatic stress disorder criteria in two samples of adolescents and young adults exposed to mass shootings: Factor analysis and comparisons to ICD-10 and DSM-IV. BMC Psychiatry, 16. http://dx.doi.org/10.1186/s12888-016-0849-y.

Hoge, C. W., Riviere, L. A., Wilk, J. E., Herrell, R. K., \& Weathers, F. W. (2014). The prevalence of post-traumatic stress disorder (PTSD) in US combat soldiers: A head-tohead comparison of DSM-5 versus DSM-IV-TR symptom criteria with the PTSD checklist. Lancet Psychiatry, 1, 269-277. http://dx.doi.org/10.1016/s2215-0366(14) 70235-4.

Hoge, C. W., Yehuda, R., Castro, C. A., McFarlane, A. C., Vermetten, E., Jetly, R., ... Rothbaum, B. O. (2016). Unintended consequences of changing the definition of posttraumatic stress disorder in DSM-5: Critique and call for action. JAMA Psychiatry, 73, 750-752. http://dx.doi.org/10.1001/jamapsychiatry.2016.0647.

Hyland, P., Brewin, C. R., \& Maercker, A. (2017). Predictive validity of ICD-11 PTSD as measured by the Impact of Event Scale-Revised: A 15-year prospective study of political prisoners. Journal of Traumatic Stress, 30, 125-132. http://dx.doi.org/10.1002/ jts. 22171.

Hyland, P., Murphy, J., Shevlin, M., Vallières, F., McElroy, E., Elklit, A., ... Cloitre, M.
(2017). Variation in post-traumatic response: The role of trauma type in predicting ICD-11 PTSD and CPTSD symptoms. Social Psychiatry and Psychiatric Epidemiology, 52, 727-736. http://dx.doi.org/10.1007/s00127-017-1350-8.

Hyland, P., Shevlin, M., Brewin, C. R., Cloitre, M., Downes, A. J., Jumbe, S., ... Roberts, N. P. (2017). Validation of posttraumatic stress disorder (PTSD) and Complex-PTSD using the International Trauma Questionnaire. Acta Psychiatrica Scandinavica Early View. http://dx.doi.org/10.1111/acps.12771.

Hyland, P., Shevlin, M., Elklit, A., Murphy, J., Vallières, F., Garvert, D. W., \& Cloitre, M. (2017). An assessment of the construct validity of the ICD-11 proposal for complex posttraumatic stress disorder. Psychological Trauma-Theory Research Practice and Policy, 9, 1-9. http://dx.doi.org/10.1037/tra0000114.

Hyland, P., Shevlin, M., McNally, S., Murphy, J., Hansen, M., \& Elklit, A. (2016). Exploring differences between the ICD-11 and DSM-5 models of PTSD: Does it matter which model is used? Journal of Anxiety Disorders, 37, 48-53. http://dx.doi.org/10. 1016/j.janxdis.2015.11.002.

Institute of Medicine (2008). Treatment of posttraumatic stress disorder: An assessment of the evidence. Washington, DC: Author.

Karatzias, T., Shevlin, M., Fyvie, C., Hyland, P., Efthymiadou, E., Wilson, D., ... Cloitre, M. (2016). An initial psychometric assessment of an ICD-11 based measure of PTSD and complex PTSD (ICD-TQ): Evidence of construct validity. Journal of Anxiety Disorders, 44, 73-79. http://dx.doi.org/10.1016/j.janxdis.2016.10.009.

Karatzias, T., Shevlin, M., Fyvie, C., Hyland, P., Efthymiadou, E., Wilson, D., ... Cloitre, M. (2017). Evidence of distinct profiles of Posttraumatic Stress Disorder (PTSD) and Complex Posttraumatic Stress Disorder (CPTSD) based on the new ICD-11 Trauma Questionnaire (ICD-TQ). Journal of Affective Disorders, 207, 181-187. http://dx.doi. org/10.1016/j.jad.2016.09.032.

Keeley, J. W., Reed, G. M., Roberts, M. C., Evans, S. C., Medina-Mora, M. E., Robles, R., ... Saxena, S. (2016a). Developing a science of clinical utility in diagnostic classification systems: Field study strategies for ICD-11 Mental and Behavioural Disorders. The American Psychologist, 71, 3-16. http://dx.doi.org/10.1037/a0039972.

Keeley, J. W., Reed, G. M., Roberts, M. C., Evans, S. C., Robles, R., Matsumoto, C., .. Maercker, A. (2016b). Disorders specifically associated with stress: A case-controlled field study for ICD-11 mental and behavioural disorders. International Journal of Clinical and Health Psychology, 16, 109-127. http://dx.doi.org/10.1016/j.ijchp.2015. 09.002.

Kliem, S., Kröger, C., Foran, H. M., Mößle, T., Glaesmer, H., Zenger, M., \& Brähler, E. (2016). Dimensional latent structure of PTSD-symptoms reporting: Is it adding by subtracting? Psychological Assessment, 28, 1663-1673. http://dx.doi.org/10.1037/ pas0000287.

Knefel, M., Garvert, D. W., Cloitre, M., \& Lueger-Schuster, B. (2015). Update to an evaluation of ICD-11 PTSD and complex PTSD criteria in a sample of adult survivors of childhood institutional abuse by Knefel \& Lueger-Schuster (2013): A latent profile analysis. European Journal of Psychotraumatology, 5. http://dx.doi.org/10.3402/ejpt. v6.25290.

Knefel, M., \& Lueger-Schuster, B. (2013). An evaluation of ICD-11 PTSD and complex PTSD criteria in a sample of adult survivors of childhood institutional abuse. European Journal of Psychotraumatology, 4. http://dx.doi.org/10.3402/ejpt.v4i0.22608.

Knefel, M., Tran, U. S., \& Lueger-Schuster, B. (2016). The association of posttraumatic stress disorder, complex posttraumatic stress disorder, and borderline personality disorder from a network analytical perspective. Journal of Anxiety Disorders, 43, 70-78. http://dx.doi.org/10.1016/j.janxdis.2016.09.002.

Kroes, M. C. W., Rugg, M. D., Whalley, M. G., \& Brewin, C. R. (2011). Structural brain abnormalities common to posttraumatic stress disorder and depression. Journal of Psychiatry \& Neurosciencei, 36, 256-265. http://dx.doi.org/10.1503/jpn.100077.

La Greca, A. M., Danzi, B. A., \& Chan, S. F. (2017). DSM-5 and ICD-11 as competing models of PTSD in preadolescent children exposed to a natural disaster: Assessing validity and co-occurring symptomatology. European Journal of Psychotraumatology, 8. http://dx.doi.org/10.1080/20008198.2017.1310591.

Larsen, S. E., \& Pacella, M. L. (2016). Comparing the effect of DSM-congruent traumas vs DSM-incongruent stressors on PTSD symptoms: A meta-analytic review. Journal of Anxiety Disorders, 38, 37-46. http://dx.doi.org/10.1016/j.janxdis.2016.01.001.

Lehrner, A., \& Yehuda, R. (2014). Biomarkers of PTSD: Military applications and considerations. European Journal of Psychotraumatology, 5. http://dx.doi.org/10.3402/ ejpt.v5.23797.

Liebschutz, J., Saitz, R., Brower, V., Keane, T. M., Lloyd-Travaglini, C., Averbuch, T., \& Samet, J. H. (2007). PTSD in urban primary care: High prevalence and low physician recognition. Journal of General Internal Medicine, 22, 719-726. http://dx.doi.org/10. 1007/s11606-00i7-0161-0.

Maercker, A., Brewin, C. R., Bryant, R. A., Cloitre, M., van Ommeren, M., Jones, L. M., .. Reed, G. M. (2013). Diagnosis and classification of disorders specifically associated with stress: Proposals for ICD-11. World Psychiatry, 12, 198-206. http://dx.doi.org/ 10.1002/wps.20057.

McNally, R. J., Robinaugh, D. J., Wu, G. W. Y., Wang, L., Deserno, M. K., \& Borsboom, D. (2015). Mental disorders as causal systems: A network approach to posttraumatic stress disorder. Clinical Psychological Science: A Journal of the Association for Psychological Science, 3, i836-849. http://dx.doi.org/10.1177/2167702614553230.

Miller, M. W., Wolf, E. J., \& Keane, T. M. (2014). Posttraumatic stress disorder in DSM-5: New criteria and controversies. Clinical Psychology: Science and Practice, 21, 208-220. http://dx.doi.org/10.1111/cpsp.12070.

Mitchell, K. S., Wolf, E. J., Bovin, M. J., Lee, L. O., Green, J. D., Rosen, R. C., ... Marx, B. P. (2017). Network models of DSM-5 posttraumatic stress disorder: Implications for ICD-11. Journal of Abnormal Psychology, 126, 355-366. http://dx.doi.org/10.1037/ abn0000252.

Morina, N., van Emmerik, A. A. P., Andrews, B., \& Brewin, C. R. (2014). Comparison of DSM-IV and proposed ICD-11 formulations of PTSD among civilian survivors of war and war veterans. Journal of Traumatic Stress, 27, 647-654. http://dx.doi.org/10. 
$1002 /$ jts. 21969.

Murphy, S., Elklit, A., Dokkedahl, S., \& Shevliin, M. (2016). Testing the validity of the proposed ICD-11 PTSD and complex PTSD criteria using a sample from Northern Uganda. European Journal of Psychotraumatology, 7. http://dx.doi.org/10.3402/ejpt. v7.32678.

Muthén, B. (2008). Latent variable hybrids - overview of old and new models. In G. R. Hancock, \& K. M. Samuelsen (Eds.). Advances in latent variable mixture models (pp. 124). Charlotte, NC: Information Age Publishing.

National Institute of Clinical Excellence (2005). The management of PTSD in adults and children in primary and secondary care. Trowbridge: Cromwell Press.

Nickerson, A., Cloitre, M., Bryant, R. A., Schnyder, U., Morina, N., \& Schick, M. (2016). The factor structure of complex posttraumatic stress disorder in traumatized refugees. European Journal of Psychotraumatology, 7. http://dx.doi.org/10.3402/ejpt.v7.33253.

O'Donnell, M. L., Alkemade, N., Nickerson, A., Creamer, M., McFarlane, A. C., Silove, D. ... Forbes, D. (2014). Impact of the diagnostic changes to post-traumatic stress disorder for DSM-5 and the proposed changes to ICD-11. The British Journal of Psychiatry, 205, 230-235. http://dx.doi.org/10.1192/bjp.bp.113.135285.

Palic, S., Zerach, G., Shevlin, M., Zeligman, Z., Elklit, A., \& Solomon, Z. (2016). Evidence of complex posttraumatic stress disorder (CPTSD) across populations with prolonged trauma of varying interpersonal intensity and ages of exposure. Psychiatry Research, 246, 692-699. http://dx.doi.org/10.1016/j.psychres.2016.10.062.

Pelcovitz, D., van der Kolk, B., Roth, S., Mandel, F., Kaplan, S., \& Resick, P. (1997). Development of a criteria set and a structured interview for disorders of extreme stress (SIDES). Journal of Traumatic Stress, 10, 3-16. http://dx.doi.org/10.1002/jts. 2490100103.

Perkonigg, A., Hofler, M., Cloitre, M., Wittchen, H. U., Trautmann, S., \& Maercker, A. (2016). Evidence for two different ICD-11 posttraumatic stress disorders in a community sample of adolescents and young adults. European Archives of Psychiatry and Clinical Neuroscience, 266, 317-328. http://dx.doi.org/10.1007/s00406-015-0639-4.

Powers, A., Fani, N., Carter, S., Cross, D., Cloitre, M., \& Bradley, B. (2017). Differential predictors of DSM-5 PTSD and ICD-11 complex PTSD among African American women. European Journal of Psychotraumatology, 8. http://dx.doi.org/10.1080/ 20008198.2017.1338914.

Rahman, A., Hamdani, S. U., Awan, N. R., Bryant, R. A., Dawson, K. S., Khan, M. F., ... van Ommeren, M. (2016). Effect of a multicomponent behavioral intervention in adults impaired by psychological distress in a conflict-affected area of Pakistan: A randomized clinical trial. JAMA, 316, 2609-2617. http://dx.doi.org/10.1001/jama.2016. 17165.

Reed, G. M. (2010). Toward ICD-11: Improving the clinical utility of WHO's International Classification of Mental Disorders. Professional Psychology-Research and Practice, 41, 457-464. http://dx.doi.org/10.1037/a0021701.

Reed, G. M., Correia, J. M., Esparza, P., Saxena, S., \& Maj, M. (2011). The WPA-WHO global survey of psychiatrists' attitudes toward mental disorders classification. World Psychiatry, 10, 118-131. http://dx.doi.org/10.1002/j.2051-5545.2011.tb00034.x.

Rosen, G. M., \& Lilienfeld, S. O. (2008). Posttraumatic stress disorder: An empirical evaluation of core assumptions. Clinical Psychology Review, 28, 837-868. http://dx. doi.org/10.1016/j.cpr.2007.12.002.

Roth, S., Newman, E., Pelcovitz, D., van der Kolk, B., \& Mandel, F. S. (1997). Complex PTSD in victims exposed to sexual and physical abuse: Results from the DSM-IV field trial for posttraumatic stress disorder. Journal of Traumatic Stress, 10, 539-555. http://dx.doi.org/10.1002/jts.2490100403.

Ruscio, A. M., Ruscio, J., \& Keane, T. M. (2002). The latent structure of posttraumatic stress disorder: A taxometric investigation of reactions to extreme stress. Journal of Abnormal Psychology, 111, 290-301. http://dx.doi.org/10.1037//0021-843x.111.2. 290.

Sachser, C., \& Goldbeck, L. (2016). Consequences of the diagnostic criteria proposed for the ICD-11 on the prevalence of PTSD in children and adolescents. Journal of Traumatic Stress, 29, 120-123. http://dx.doi.org/10.1002/jts.22080.
Sachser, C., Keller, F., \& Goldbeck, L. (2016). Complex PTSD as proposed for ICD-11: Validation of a new disorder in children and adolescents and their response to trauma-focused cognitive behavioral therapy. Journal of Child Psychology and Psychiatry, 58, 160-168. http://dx.doi.org/10.1111/jcpp.12640.

Scheeringa, M. S., Zeanah, C. H., \& Cohen, J. A. (2011). PTSD in children and adolescents: Toward an empirically based algorithm. Depression and Anxiety, 28, 770-782. http:// dx.doi.org/10.1002/da.20736.

Shevlin, M., Hyland, P., Karatzias, T., Fyvie, C., Roberts, N., Bisson, J. I., ... Cloitre, M. (2017). Alternative models of disorders of traumatic stress based on the new ICD-11 proposals. Acta Psychiatrica Scandinavica, 135, 419-428. http://dx.doi.org/10.1111/ acps.12695.

Spitzer, R. L., First, M. B., \& Wakefield, J. C. (2007). Saving PTSD from itself in DSM-V. Journal of Anxiety Disorders, 21, 233-241. http://dx.doi.org/10.1016/j.janxdis.2006 09.006.

Stammel, N., Abbing, E. M., Heeke, C., \& Knaevelsrud, C. (2015). Applicability of the ICD11 proposal for PTSD: A comparison of prevalence and comorbidity rates with the DSM-IV PTSD classification in two post-conflict samples. European Journal of Psychotraumatology, 6. http://dx.doi.org/10.3402/ejpt.v6.27070.

Stein, D. J., McLaughlin, K. A., Koenen, K. C., Atwoli, L., Friedman, M. J., Hill, E. D., ... Kessler, R. C. (2014). DSM-5 and ICD-11 definitions of posttraumatic stress disorder: Investigating "narrow" and "broad" approaches. Depression and Anxiety, 31, 494-505. http://dx.doi.org/10.1002/da.22279.

Tay, A. K., Rees, S., Chen, J., Kareth, M., \& Silove, D. (2015). The structure of posttraumatic stress disorder and complex post-traumatic stress disorder amongst West Papuan refugees. BMC Psychiatry, 15. http://dx.doi.org/10.1186/s12888-0150480-3.

van der Kolk, B. A., Roth, S., Pelcovitz, D., \& Mandel, F. (1993). Complex PTSD: Results of the PTSD field trial for DSM-IV. Washington, DC: American Psychiatric Association.

van der Kolk, B. A., Roth, S., Pelcovitz, D., Sunday, S., \& Spinazzola, J. (2005). Disorders of extreme stress: The empirical foundation of a complex adaptation to trauma. Journal of Traumatic Stress, 18, 389-399. http://dx.doi.org/10.1002/jts.20047.

van Emmerik, A. A. P., \& Kamphuis, J. H. (2011). Testing a DSM-5 reformulation of posttraumatic stress disorder: Impact on prevalence and comorbidity among treatment-seeking civilian trauma survivors. Journal of Traumatic Stress, 24, 213-217. http://dx.doi.org/10.1002/jts.20630.

Vermetten, E., Baker, D. G., Jetly, R., \& McFarlane, A. C. (2016). Concerns over divergent approaches in the diagnostics of posttraumatic stress disorder. Psychiatric Annals, 46, 498-509. http://dx.doi.org/10.3928/00485713-20160728-02.

Walton, J. L., Cuccurullo, L.-A. J., Raines, A. M., Vidaurri, D. N., Allan, N. P., Maieritsch, K. P., \& Franklin, C. L. (2017). Sometimes less is more: Establishing the core symptoms of PTSD. Journal of Traumatic Stress, 30, 254-258. http://dx.doi.org/10.1002/ jts. 22185.

Weiss, D. S., \& Marmar, C. R. (1996). The Impact of Event Scale-Revised. In J. Wilson, \& T. M. Keane (Eds.). Assessing psychological trauma and PTSD (pp. 399-411). New York: Guilford.

Wisco, B. E., Miller, M. W., Wolf, E. J., Kilpatrick, D., Resnick, H. S., Badour, C. L., .. Friedman, M. J. (2016). The impact of proposed changes to ICD-11 on estimates of PTSD prevalence and comorbidity. Psychiatry Research, 240, 226-233. http://dx.doi. org/10.1016/j.psychres.2016.04.043.

Wolf, E. J., Miller, M. W., Kilpatrick, D., Resnick, H. S., Badour, C. L., Marx, B. P., ... Friedman, M. J. (2015). ICD-11 complex PTSD in U.S. national and veteran samples: Prevalence and structural associations with PTSD. Clinical Psychological Science: A Journal of the Association for Psychological Science, 3, 215-229. http://dx.doi.org/10. $1177 / 2167702614545480$.

Zelazny, K., \& Simms, L. J. (2015). Confirmatory factor analyses of DSM-5 posttraumatic stress disorder symptoms in psychiatric samples differing in Criterion A status. Journal of Anxiety Disorders, 34, 15-23. http://dx.doi.org/10.1016/j.janxdis.2015.05. 009. 